\title{
Flora da Bahia: Leguminosae - Hymenaea (Caesalpinioideae: Detarieae)
}

\author{
Isys Mascarenhas Souza*, Ligia Silveira Funch ${ }^{\text {a }}$ Luciano Paganucci de Queiroz ${ }^{\text {b }}$
}

Programa de Pós-Graduação em Botânica, Universidade Estadual de Feira de Santana, Feira de Santana, Bahia, Brasil.

\begin{abstract}
Resumo - É apresentado aqui o tratamento taxonômico de Hymenaea (Leguminosae) do estado da Bahia, Brasil. São reconhecidas 11 espécies; H. altissima, H. maranhensis e H. rubriflora var. rubriflora são registradas pela primeira vez no estado. O trabalho inclui chave de identificação, descrições, comentários, mapas de distribuição das espécies no estado e ilustrações de caracteres diagnósticos.

Palavras-chave adicionais: Brasil, Fabaceae, floristics, jatobá, Nordeste, taxonomia.
\end{abstract}

\begin{abstract}
Flora of Bahia: Leguminosae - Hymenaea (Caesalpinioideae: Detarieae)) - The taxonomic treatment of Hymenaea (Leguminosae) from the state of Bahia, Brazil, is presented here. We recognize 11 species; H. altissima, H. maranhensis, and H. rubriflora var. rubriflora are reported for the first time in the state. An identification key, descriptions, comments, distribution maps of species in the state and illustrations of diagnostic characters are presented.
\end{abstract}

Additional key words: Fabaceae, floristics, jatobá, Northeast Brazil, taxonomy.

Leguminosae inclui cerca de 727 gêneros e 19.327 espécies e está distribuída em todos os continentes, com exceção da Antártica (Lewis et al. 2005). No Brasil, ocorrem 221 gêneros e 2.809 espécies, sendo 156 gêneros e 925 espécies referidas para a Bahia (Fabaceae in Flora do Brasil 2020). A família caracteriza-se pela combinação de folhas alternas, compostas, com estípulas; flores geralmente pentâmeras, diclamídeas, diplostêmones; ovário súpero, unicarpelar, unilocular, placentação marginal; frutos tipicamente legumes, mas comumente folículos, legumes indeiscentes, legumes bacáceos, craspédios, lomentos, sâmaras e drupas; sementes com embrião conspícuo, praticamente sem endosperma, com ou sem arilo (Queiroz 2009).

\section{Hymenaea L.}

Árvores ou arbustos; tronco acinzentado, com lenticelas e glândulas resiníferas; ramos glabros a indumentados. Estípulas precocemente caducas. Folhas bifolioladas, pecioladas ou subsésseis; folíolos obovais, oblongos, elípticos ou ovais, falcados ou não, ápice obtuso, arredondado, retuso, agudo, mucronulado ou cuspidado, raramente emarginado, base oblíqua, lado interno agudo ou arredondado, lado externo leve a fortemente arredondado, margem inteira, plana ou revoluta, cartáceos ou coriáceos, glabros a indumentados, com pontuações translúcidas. Panículas congestas ou laxas, mais curtas ou mais longas que a folha adjacente, indumento semelhante aos ramos; bractéolas caducas. Flores actinomorfas, hipanto campanulado ou obcônico, com ou sem alongamento na base, com disco nectarífero; sépalas 4 , carnosas, imbricadas, indumentadas; pétalas 5 , brancas ou avermelhadas, obovais, elípticas ou espatuladas,

\footnotetext{
*Autora para correspondência: isys.souza@gmail.com;

aligiafunch@yahoo.com; bluciano.paganucci@gmail.com

Editor responsável: Alessandro Rapini

Submetido: 30 maio 2016; aceito: 5 out. 2016

Publicação eletrônica: 27 out. 2016; versão final: 31 out. 2016
}

sésseis, subsésseis ou unguiculadas; estames 10 , filetes brancos, glabros ou glabrescentes, com ou sem glândulas, anteras rimosas; ovário oblongo, glabro ou indumentado, curto ou longamente estipitado, adnato à parede do hipanto. Frutos legumes indeiscentes, oblongos, elípticos, orbiculares ou obovoides, cilíndricos ou lateralmente achatados, constritos ou não entre as sementes, lenhosos, castanhos, glabros ou indumentados; sementes 1-8, ovoides, obovoides ou elipsoides, testa castanha, endocarpo farináceo.

De Candolle (1825) posicionou Hymenaea na tribo Cassieae (Caesalpinioideae), mas estudos posteriores consideraram o gênero em Detarieae (Lee \& Langenhaim 1975; Mackinder 2005). Análises com dados morfológicos e moleculares sustentam o monofiletismo da tribo Detarieae, onde o clado Hymenaea revela a estreita afinidade entre os gêneros Hymenaea, Guibourtia Benn. e Peltogyne Vogel, caracterizado pelas folhas bifolioladas, folíolos assimétricos com nervura primária próxima à margem distal, e estípulas inseridas lateralmente (FougèreDanezan et al. 2010). Além disso, Hymenaea ainda é facilmente diagnosticada pelo peciólulo retorcido e pontuações translúcidas nos folíolos (Lee \& Langenheim 1975) com grande variação em relação à distribuição na lâmina foliar (Figura 1).

Lee \& Langenheim (1975) revisaram o gênero e propuseram o reconhecimento de duas seções: 1Hymenaea, caracterizada por inflorescências curtopaniculadas, $8-15 \mathrm{~cm}$ compr., corimbosas quando maduras, com flores de tamanho médio a grande (Figura 2); e 2- Trachylobium (Hayne) Baill., caracterizada por inflorescências longo-paniculadas, 18-35 cm compr., com flores pequenas (Figura 3). Pestana (2010) propôs as sinonimizações da espécie dúbia $H$. capanema a $H$. courbaril var. courbaril, e das variedades de $H$. stigonocarpa. Entretanto, os argumentos para estas últimas sinonimizações estão baseados sobretudo em "incoerências" na literatura e não são satisfatórios. Recentemente, estudos 


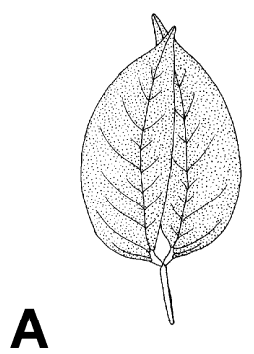

B

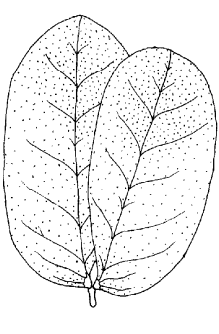

C
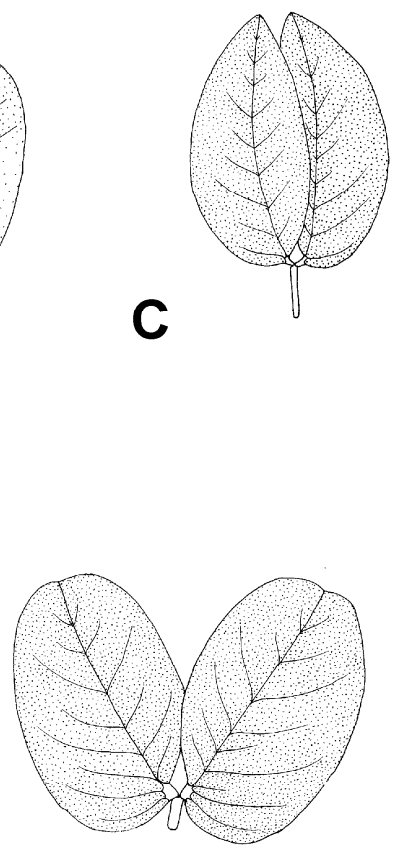

E
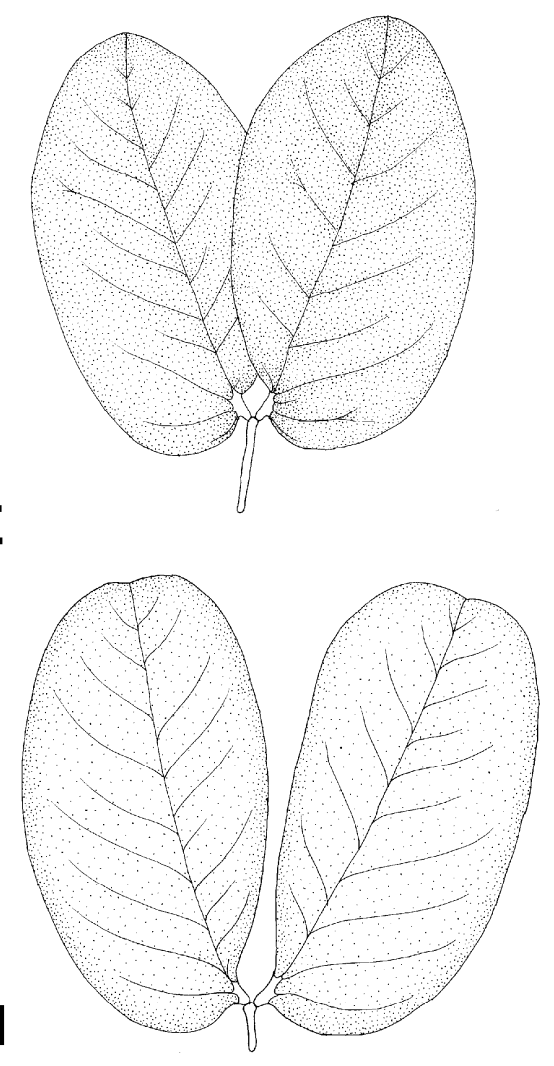

F

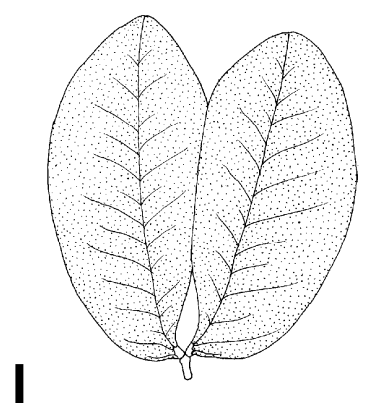

D

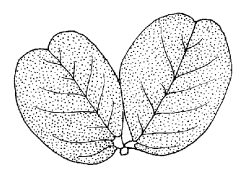

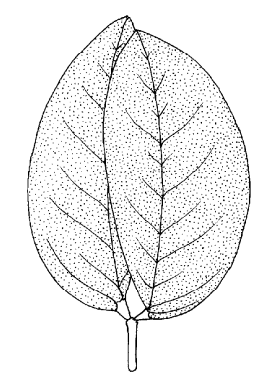

G

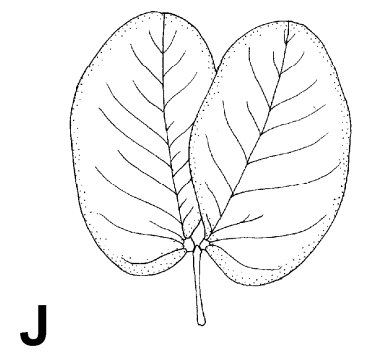

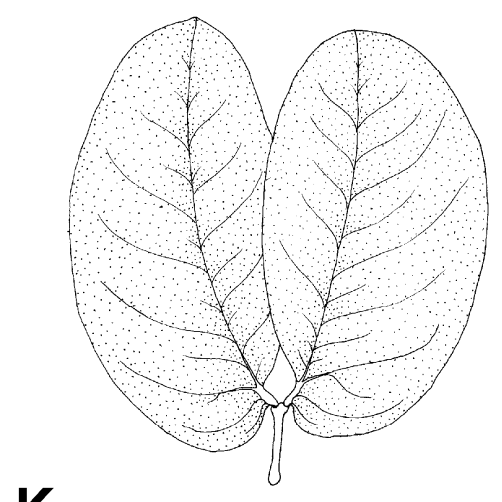

K

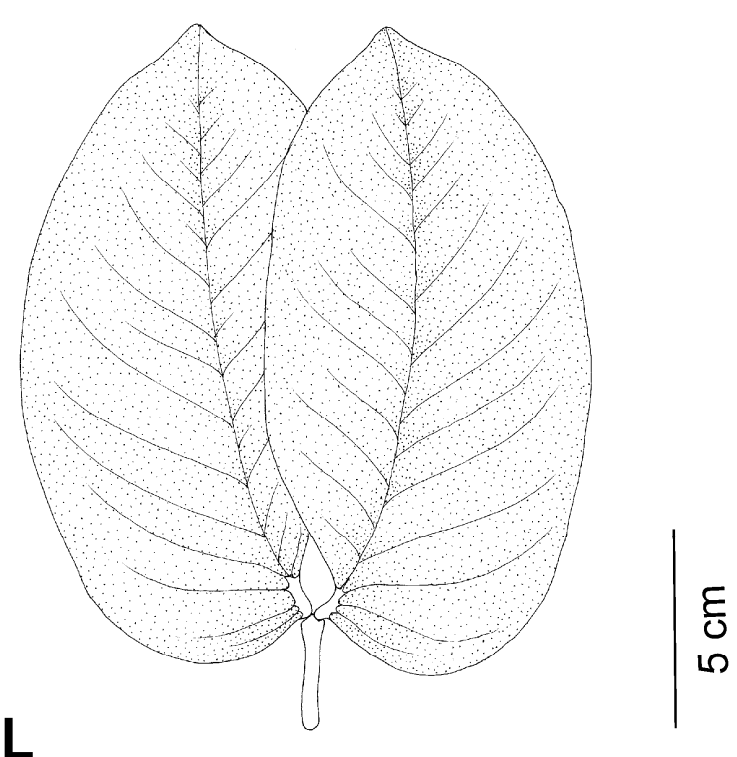

Figura 1. Folhas das espécies de Hymenaea do estado da Bahia: A- H. altissima (Sambuichi 1169A); B- H. aurea (Santos 840); C- H. courbaril (Souza 80); D- H. eriogyne (Conceição 1560); E- H. longifolia (Queiroz 4171); F- H. maranhensis (Machado 108); G- H. martiana (Queiroz 7711); H- H. oblongifolia var. latifolia (Souza 160); I- H. rubriflora var. rubriflora (Monteiro 22700); J- H. velutina (Queiroz 7994); K- H. stigonocarpa var. stigonocarpa (Souza 95); L- H. stigonocarpa var. pubescens (Walter 221) (Ilustração: I.M. Souza). 


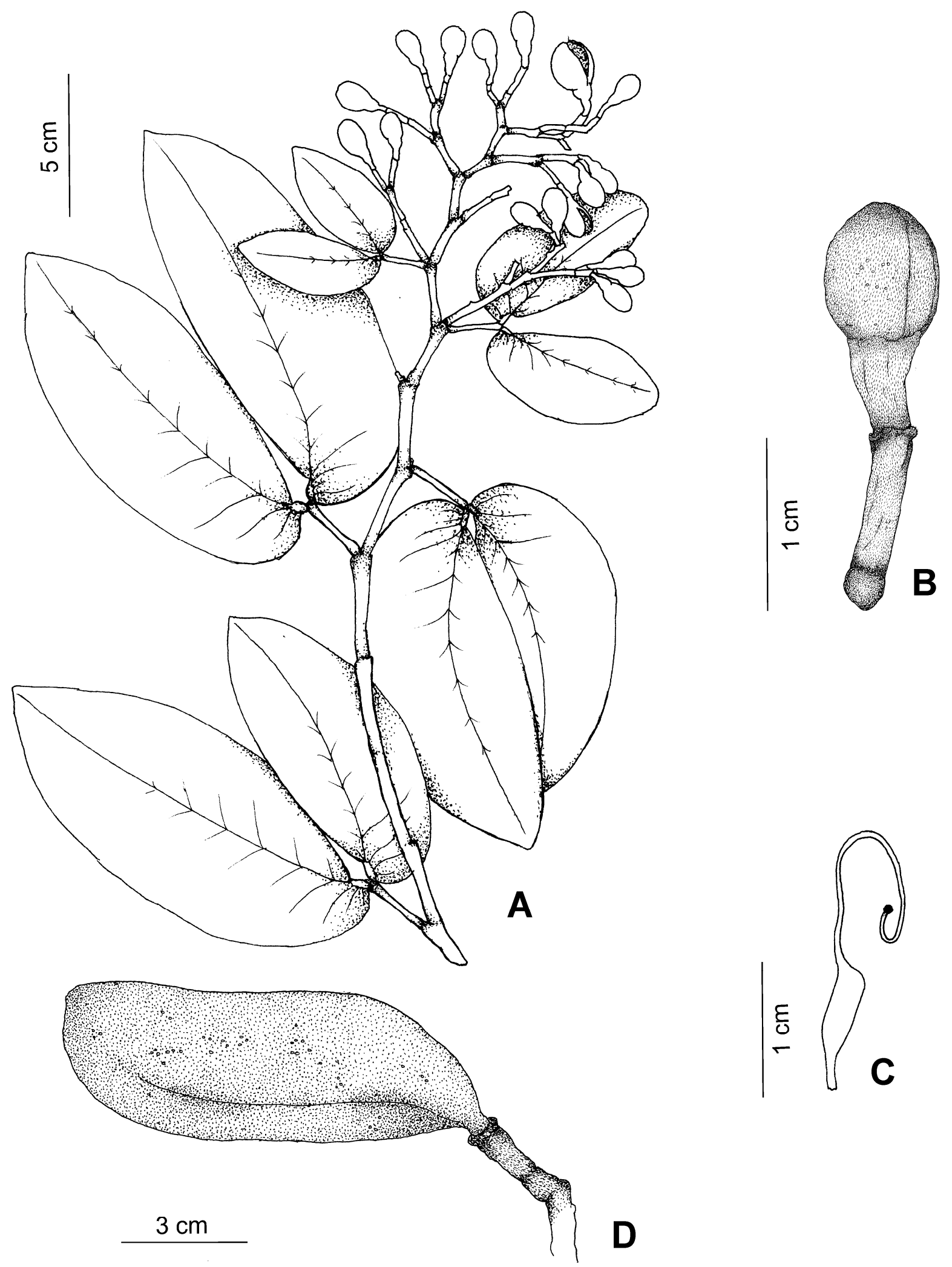

Figura 2. Características diagnósticas de Hymenaea seção Hymenaea. A, B. H. longifolia: A- ramo com botões florais; B- botão floral (Queiroz 4171). C, D. H. velutina: C- ovário; D- fruto (Queiroz 7994). (Ilustração: I.M. Souza).

morfométricos com análises multivariadas propuseram a elevação de duas variedades de $H$. courbaril à categoria de espécie (Souza et al. 2014), e uma nova espécie foi descrita para a Mata Atlântica, no Espírito Santo (Ribeiro et al. 2015).
Hymenaea é predominantemente neotropical, com distribuição disjunta na costa leste da África, onde ocorre apenas uma espécie (Lee \& Langenheim 1975; Mackinder 2005). Atualmente, reúne 17 espécies (Mackinder 2005; Souza et al. 2014; Ribeiro et al. 


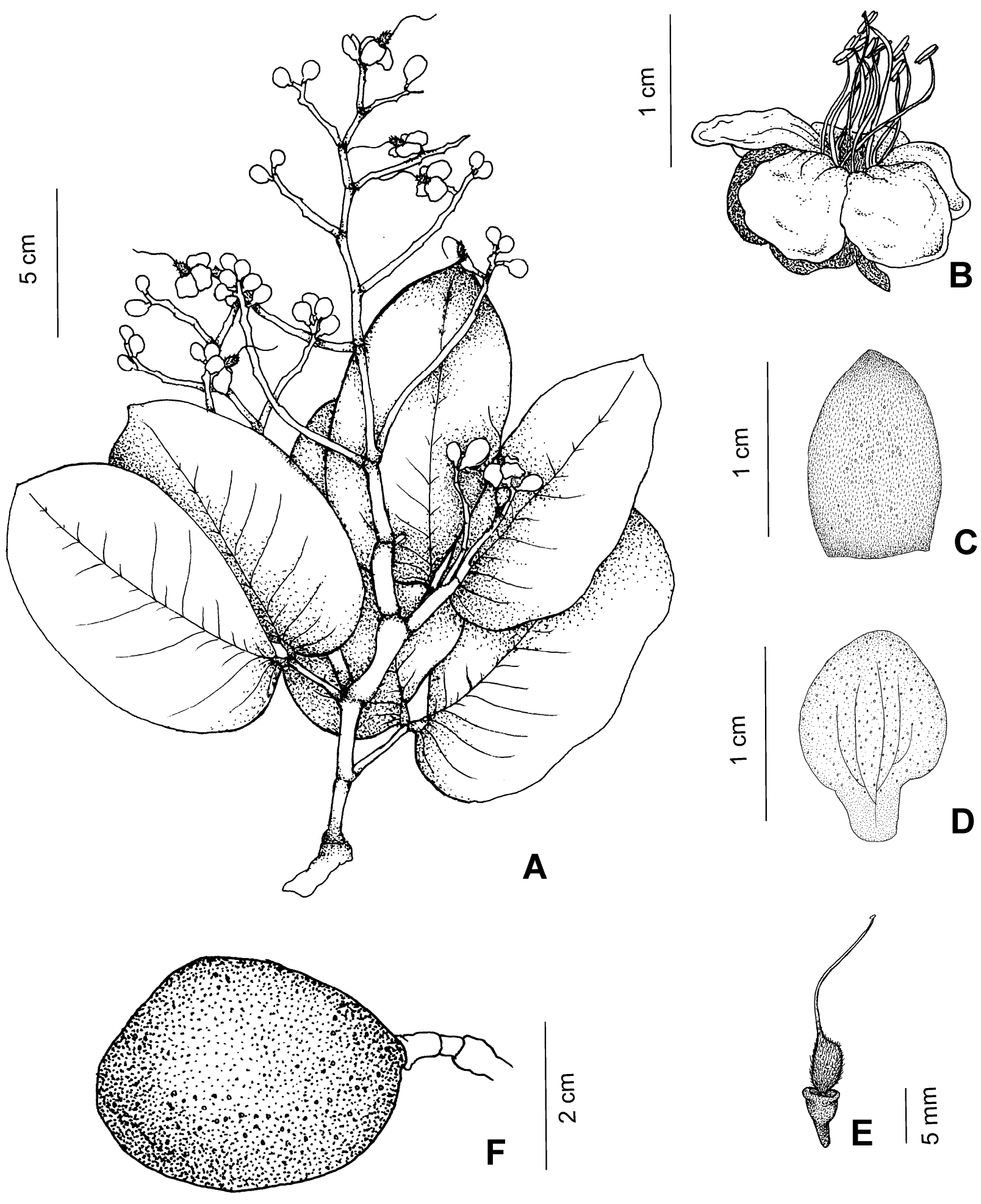

Figura 3. Características diagnósticas de Hymenaea seção Trachylobium. Hymenaea oblongifolia var. latifolia: A- ramo com botões e flores; B- flor; C- sépala; D- pétala; E- ovário; F- fruto (Souza 160). (Ilustração: I.M. Souza).

2015), sendo 15 citadas para o Brasil (Lima \& Pinto 2015) e 11 para a Bahia (Souza 2013), onde ocorrem em áreas de Caatinga, Cerrado e Mata Atlântica. Além de importantes ecologicamente, especialmente no tocante às interações com polinizadores (Gibbs et al.
1999) e dispersores (Asquith et al. 1999), suas espécies há muito são utilizadas por populações humanas que exploram sua madeira, resina, casca, folhas e frutos (Langenheim 1969; Lee \& Langenheim 1975; Lewis et al. 2005; Aquino et al. 2007). 


\section{Chave para as espécies e variedades}

1. Folíolos ovais, elípticos ou estreito-elípticos, ápice agudo ou acuminado.

2. Ramos e folíolos indumentados; ovário com um tufo de tricomas na base

2'. Ramos e folíolos glabros ou glabrescentes; ovário glabro.

3. Folíolos 2-2,5 cm larg., raramente maiores, fortemente falcados, lado externo da base truncado (florestas úmidas da região costeira)

3'. Folíolos 2,8-6,5 cm larg., ligeiramente falcados, lado externo da base arredondado ou ligeiramente arredondado (florestas secas, bem distribuídas no interior e oeste do Estado).

4. Pecíolo 2,6-3 cm compr.; peciólulos 7-8 mm compr.; folíolos 10,1-12,5 × 4,5-6,5 cm

4'. Pecíolo 1,1-1,6 cm compr.; peciólulos 4-5 mm compr.; folíolos 6-9 × 2,8-4 cm ...... 3. H. courbaril

1'. Folíolos obovais ou oblongos, ápice arredondado ou obtuso.

5. Ramos e folíolos glabros.

6. Folíolos 4,5-8 cm compr., raramente maiores, lado externo da base cordado, pontuações translúcidas restritas à margem da lâmina; inflorescências congestas; flores 25-27 mm compr.; hipanto 12-18 mm compr.; filetes 27-49 mm compr., com glândulas, anteras 6-7 mm compr.; ovário glabro; frutos 7,5$16,8 \mathrm{~cm}$ compr., oblongos ou elípticos, glabros, com estrias

11. H. velutina

6'. Folíolos 9,3-19,6 cm compr., lado externo da base arredondado, pontuações translúcidas em toda a lâmina, concentradas na margem; inflorescências laxas; flores 14-16 mm compr.; hipanto ca $5 \mathrm{~mm}$ compr.; filetes 14-23 mm compr., sem glândulas, anteras ca. $3 \mathrm{~mm}$ compr.; ovário indumentado; frutos 4,1-6,4 cm compr., orbiculares ou obovoides, levemente indumentado na base, sem estrias

\section{H. oblongifolia}

5'. Ramos e folíolos indumentados, ao menos quando jovens.

7. Folíolos $2-7,5 \mathrm{~cm}$ compr.; pecíolo $0,2-0,7 \mathrm{~mm}$ compr.; ovário totalmente indumentado.

8. Folíolos $2-5 \mathrm{~cm}$ compr., cartáceos a coriáceos, pontuações translúcidas distribuídas uniformemente na lâmina, indumento pouco evidente, tricomas curtos, translúcidos ou ferrugíneo ..... 4. H. eriogyne

8'. Folíolos 5,1-7,5 cm compr., membranáceos a cartáceos, pontuações translúcidas distribuídas não uniformemente, concentradas na porção distal da lâmina, indumento bastante evidente, tricomas longos e dourados

2. H. aurea

7'. Folíolos 8-13 cm compr.; pecíolo 0,8-2,2 cm compr.; ovário glabro ou parcialmente indumentado.

9. Pecíolo ca. 0,8 cm compr.; folíolos com face adaxial brilhante, margem fortemente revoluta; flores 22-30 mm compr.

9. H. rubriflora var. rubriflora

9'. Pecíolo 0,9-2,2 cm compr.; folíolos com face adaxial glauca, margem plana ou ligeiramente revoluta; flores de $35-52 \mathrm{~mm}$ compr.

10. Pecíolo ca. 0,9 cm compr.; folíolos com margem ligeiramente revoluta; pétalas $17-20 \mathrm{~mm}$ compr., espatuladas; ovário parcialmente indumentado

6. H. maranhensis

10'. Pecíolo 1-4 cm compr.; folíolos com margem plana; pétalas $23-28 \mathrm{~mm}$ compr., elípticas ou obovais; ovário glabro

10. H. stigonocarpa

11. Ramos glabros; pecíolo 1-2,2 cm compr.; folíolos 8-13 cm compr.

10.2. H. stigonocarpa var. stigonocarpa

11'. Ramos densamente indumentados; pecíolo 2,5-4 cm compr.; folíolos 12,5-17,5 cm compr. 10.1. H. stigonocarpa var. pubescens

1. Hymenaea altissima Ducke, Ann. Acad. Brasil. Sci. 7(3): 207. 1935.

Figuras 1A e 4; Lee \& Langenheim (1975: fig. 26M-O).

Árvore $10-38 \mathrm{~m}$ alt.; tronco ca. $51 \mathrm{~cm}$ de perímetro, ramos glabros, raramente glabrescentes, tricomas ferrugíneos, curtos, sinuosos, prostrados. Pecíolo 1-1,3(-1,7) cm compr.; peciólulos 0,3-0,4($0,5) \mathrm{cm}$ compr.; folíolos $4-5,7(-6,4) \times 2-2,5 \mathrm{~cm}$, ovais, estreito-elípticos ou elípticos, fortemente falcados, ápice agudo ou acuminado, base oblíqua, lado interno agudo, o externo truncado, margem ligeiramente revoluta, cartáceos, faces adaxial e abaxial glabras, raramente glabrescentes, nervura primária visível na face adaxial, proeminente na abaxial, as secundárias levemente visíveis em ambas as faces, pontuações translúcidas em toda a lâmina. Panículas 3,5-4,4(14,7) $\mathrm{cm}$ compr., congestas, mais curtas que a folha adjacente; pedicelos 0,4-0,7 cm compr. Flores 20-27 $\mathrm{mm}$ compr.; hipanto 7-12 $\mathrm{mm}$ compr., campanulado, base alongada (3-5 mm compr.); sépalas 10-16 × 7-11 $\mathrm{mm}$, ovais ou largo-ovais, externamente tomentosas, internamente seríceas; pétalas 10-16 × 5-7 mm, obovais ou largo-obovais, sésseis; filetes $18-25 \mathrm{~mm}$ compr., glabrescentes, com glândulas, anteras $4-5 \mathrm{~mm}$ compr.; ovário 5-6 × 2-3 mm, oblongo, glabro, estípite 2-3 mm compr., estilete 13-19 mm compr. Frutos ca. $7,6 \times 3,3 \times 2,5 \mathrm{~cm}$, oblongos, cilíndricos, irregularmente constritos entre as sementes, superfície brilhante, rugosa, glabra, sem estrias, sutura proeminente. 
Até então conhecida apenas para a Região Sudeste (Espírito Santo, Rio de Janeiro e São Paulo), na Mata Atlântica (Lima \& Pinto 2015), é registrada aqui pela primeira vez para a Bahia, ocorrendo no litoral sul. G8: Mata Atlântica (florestas ombrófilas densas). Floração: novembro a abril; frutificação: janeiro.

Material examinado - Ilhéus, $14^{\circ} 42^{\prime} 33^{\prime \prime} \mathrm{S}, 39^{\circ} 11^{\prime} 7^{\prime \prime} \mathrm{W}, 10$ abr. 2001 (bot.), R.H.R. Sambuichi 1169A (CEPEC).

Material adicional - BRASIL. ESPÍRITO SANTO: Linhares, 19²3'28"S, 4004'20"W, 19 dez. 1979 (fl.), D.A. Folli 181 (RB). SÃO PAULO: São Paulo, 16 fev. 1978 (fl.), M. Kirizawa et al. 326 (CEPEC, SP).

Hymenaea altissima foi descrita por Ducke (1935) e, posteriormente, tratada como variedade de $H$. courbaril por Lee \& Langenheim (1974), sob o argumento de que os caracteres foliares e o tamanho das flores não seriam significativos para garantir o status de espécie. Contudo, a morfometria combinada a análises multivariadas sustenta sua manutenção como espécie a parte (Souza et al. 2014). Pode ser reconhecida pela presença de folíolos fortemente falcados, usualmente bem estreitos (2-2,5 cm larg.), e pecíolos (1-1,3 cm compr.) glabros. Difere das demais espécies que ocorrem na Mata Atlântica da Bahia $(H$. aurea, $H$. oblongifolia e $H$. rubriflora) pelos folíolos mais curtos (4-5,7 cm vs. 5,1-19,6 cm compr.) e estreitos (2-2,5 cm vs. 2,7-9,3 cm larg.), ovário glabro (vs. totalmente indumentado ou com tufo de tricomas na base) e pétalas sésseis (vs. unguiculadas). Além disso, possui folíolos glabros (vs. indumentados em $H$. rubriflora).

2. Hymenaea aurea Y.T.Lee \& Langenh., J. Arnold Arbor. 54(1): 96; figs 1 e 2. 1973.

Figuras 1B e 4; Lee \& Langenheim (1973: fig. 2)

Árvore 3-40 m alt.; tronco $50-60 \mathrm{~cm}$ de perímetro; ramos indumentados nas extremidades, tricomas dourados, longos, sinuosos ou eretos. Pecíolo 0,4 0,7(-0,9) cm compr.; peciólulos 0,2-0,6 cm compr.; folíolos $5,1-7,5(-10) \times 2,7-4(-4,9) \mathrm{cm}$, obovais, raramente elípticos ou oblongos, ápice arredondado, obtuso, mucronulado, cuspidado, raramente emarginado, base oblíqua, lado interno agudo, o externo truncado a arredondado, margem ligeira a fortemente revoluta, membranáceos ou cartáceos, face adaxial glabra a glabrescente, a abaxial densamente indumentada, nervuras primária e secundárias sutilmente visíveis na face adaxial, proeminentes na abaxial, pontuações translúcidas concentradas na porção distal da lâmina. Panículas 7,5-28 cm compr., congestas, mais longas que a folha adjacente; pedicelos 0,4-1,4 cm compr. Flores 31-37 mm compr.; hipanto 8-25 mm compr., campanulado, base alongada (3-15 $\mathrm{mm}$ compr.); sépalas 13-14 × 4-6 mm, obovais, externa e internamente seríceo-tomentosas; pétalas 7 15 x 3-5 mm, espatuladas, unguiculadas (base 4-7 cm compr.); filetes 21-31 mm compr., glabrescentes, com glândulas, anteras 6-7 mm compr.; ovário 7-10 × 3-4 $\mathrm{mm}$, oblongo, densamente indumentado, estípite 2-6 mm compr., estilete 30-34 mm compr. Frutos 6,8-9,5 $\times 3,1-4,6 \times 2,1-2,6 \mathrm{~cm}$, oblongos, cilíndricos ou lateralmente achatados, irregularmente constritos entre as sementes, superfície opaca, finamente granulosa, indumentada, sem estrias, sutura proeminente ou não.

Endêmica da Mata Atlântica brasileira, foi originalmente considerada exclusiva das florestas perenifólias da região costeira do sul da Bahia (Lee \& Langenheim 1973, 1975), tendo sido registrada posteriormente para o Espírito Santo e o Rio de Janeiro (Lima \& Pinto 2015). G8, H8, I8: Mata Atlântica (florestas ombrófilas densas). Floração: novembro; frutificação: novembro a junho.

Material selecionado - Ilhéus, 10 nov. 1979 (bot.), S.A. Mori \& F. Benton 12992 (CEPEC, HRB); Porto Seguro, 16 22'29"S, 3906'36"W, 23 nov. 2000 (fr.), A.A. Santos et al. 840 (HUEFS); Santa Cruz Cabrália, 16¹6'S, 3901'W, 22 out. 1999 (est.), M.L. Guedes et al. 6754 (CEPEC); Una, 11 nov. 1980 (est.), A. Rylands \& J.L. Hage 72 (CEPEC, HRB).

Hymenaea aurea é facilmente diagnosticada pela presença de um denso indumento dourado nos ramos mais jovens, pecíolos, folhas, botões e flores. Assemelha-se a $H$. eriogyne, que ocorre na Caatinga e pode ser encontrada na forma de arbustos, alcançando no máximo $12 \mathrm{~m}$ de altura, com indumento menos denso nos ramos e panículas. Em relação às espécies da Mata Atlântica, difere de $H$. oblongifolia var. latifolia pelas folhas menores $(5,1-7,5 \mathrm{~cm}$ vs. 9,3$19,6 \mathrm{~cm}$ compr.) e indumentadas (vs. glabras), flores de tamanho médio (31-37 mm vs. 14-16 mm compr.) em inflorescências congestas (vs. laxas) e frutos maiores (6,8-9,5 cm vs. 4,1-6,4 cm compr.). Difere de $H$. altissima e $H$. rubriflora var. rubriflora principalmente pelas pétalas espatuladas (vs. elípticas ou obovais) e ovário indumentado (vs. glabro).

\section{Hymenaea courbaril L., Sp. Pl. 2: 1192. 1753.}

Figuras 1C, 4 e 11A-C; Lee \& Langenheim (1975: fig. 26A-L, P-R).

Árvore 8-30 $\mathrm{m}$ alt.; tronco 80-200 cm de perímetro; ramos glabros, raramente glabrescentes, tricomas ferrugíneos, curtos, sinuosos. Pecíolo 1,11,7(-2) cm compr.; peciólulos 0,4-0,5 cm compr.; folíolos $6-9(-10,2) \times 2,8-4(-5,1) \mathrm{cm}$, elípticos, raramente ovais, ligeiramente falcados, ápice agudo, menos frequente obtuso, raramente acuminado, base oblíqua, lado interno agudo, o externo ligeiramente arredondado, margem ligeiramente revoluta, cartáceos ou coriáceos, faces adaxial e abaxial glabras, raramente glabrescentes, nervuras primária e secundárias sutilmente visíveis na face adaxial, proeminentes na abaxial, pontuações translúcidas em toda a lâmina. Panículas 4,3-8,5 cm compr., congestas, mais curtas ou com o mesmo comprimento da folha adjacente; pedicelos 0,3-0,5 cm compr. Flores 24-31 $\mathrm{mm}$ compr.; hipanto 7-15 mm compr., campanulado, base alongada (4-9 mm compr.); sépalas 12-15 × 7-12 mm, ovais, largo-ovais ou oblongas, externamente seríceotomentosas ou tomentosas, internamente seríceas; 
pétalas 11-12 × 6-8 $\mathrm{mm}$, ovais ou largo-elípticas, sésseis; filetes 14-22 mm compr., glabrescentes, com glândulas, anteras $4-7 \mathrm{~mm}$ compr.; ovário $5-8 \times 2-4$ $\mathrm{mm}$, oblongo, glabro, estípite 2-4 mm compr., estilete 11-22 mm compr. Frutos 9,3-14,6 × 4,3-5,6 × 2,1-4 $\mathrm{cm}$, oblongos ou obovais, cilíndricos ou lateralmente achatados, sem constrições entre as sementes, superfície brilhante, rugosa, glabra, sem estrias, sutura proeminente.

Amplamente distribuída, desde o México, passando pela América Central e Antilhas, até a América do Sul (Bolívia, Colômbia, Guiana, Guiana Francesa, Suriname, Venezuela e Brasil; Lee \& Langenheim 1975). No Brasil, está representada em todas as Regiões e em praticamente todos os domínios, Amazônia, Caatinga, Cerrado, Mata Atlântica e Pantanal (Lima \& Pinto 2015). D5, D7, E3, E6, E7, F4, F9, G5, G6, G7: Caatinga, Cerrado e Mata Atlântica (florestas estacionais). Floração: outubro a abril; frutificação: novembro a julho.

Material selecionado - Baianópolis, $12^{\circ} 20^{\prime} \mathrm{S}, 44^{\circ} 31^{\prime} \mathrm{W}, 20$ nov. 1980 (bot., fl.), S.B. Silva 157 (HRB); Bom Jesus da Lapa, 6 abr. 1992 (est.), S.M. Faria et al. 427 (RB); Caetité, 14º'10'S, $42^{\circ} 32^{\prime} \mathrm{W}, 27$ out. 1993 (bot., fl.), L.P. Queiroz \& N.S. Nascimento 3614 (HRB, HUEFS, SPF); Gentio do Ouro, 11'36'49"S, 4236'52"W, 22 jul. 2000, K.R. Leite et al. 108 (HUEFS, SPF); Itaetê, 19 jan. 2012 (fl.), I.M. Souza 91 (HUEFS); Jacobina,

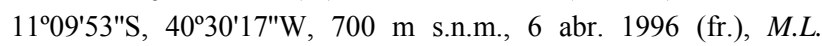
Guedes et al. in PCD 2871 (SPF); Livramento do Brumado, $14^{\circ} 37^{\prime} \mathrm{S}, 41^{\circ} 47^{\prime} \mathrm{W}, 28$ out. 1993 (fl.), L.P. Queiroz \& N.S. Nascimento 3663 (HUEFS, RB); Mucugê, 1257'50"S, 41'28'25"W, 16 jul. 1996 (fr.), R.M. Harley in PCD 3702 (HUEFS); Palmeiras, 17 dez. 2011 (bot.), I.M. Souza 80 (HUEFS); Ruy Barbosa, 12²19'43"W, 40²8'34"W, 19 set. 2005 (fr.), D. Cardoso 768 (HUEFS).

É reconhecida pelo hábito sempre arbóreo, com copa frondosa, tronco ereto e periderme não

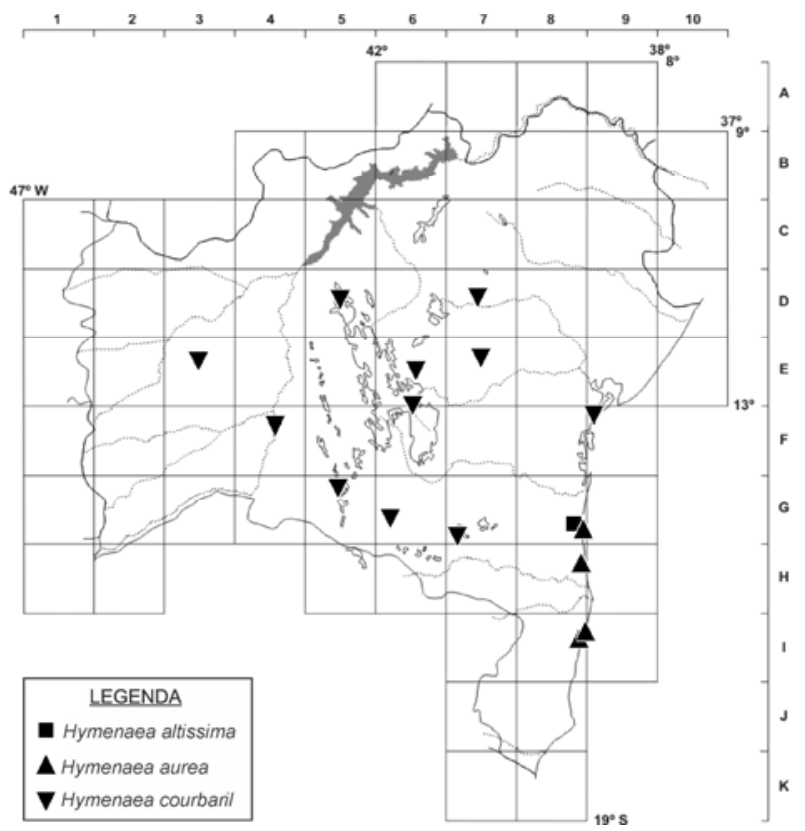

Figura 4. Distribuição geográfica de Hymenaea altissima, H. aurea e $H$. courbaril no estado da Bahia. descamante, folíolos normalmente elípticos, com ápice agudo, ligeiramente falcados e glabros, flores de tamanho médio (24-31 $\mathrm{mm}$ compr.), hipanto campanulado e ovário glabro, com estípite $(2-4 \mathrm{~mm}$ compr.). Pode ocorrer no mesmo ambiente que $H$. martiana e $H$. stigonocarpa, porém a primeira apresenta indumento nos ramos, folíolos e ovário, e a segunda normalmente apresenta hábito arbustivo, tronco retorcido, periderme descamante, folíolos normalmente obovados, com mais de $8 \mathrm{~cm}$ de comprimento, indumentados, e flores maiores (35-52 mm compr.). Lee \& Langenheim (1974) reconheceram seis variedades para $H$. courbaril, enquanto Souza et al. (2014) reconhececeram três espécies neste complexo: H. altissima, $H$. courbaril e $H$. longifolia. Hymenaea courbaril difere de $H$. longifolia principalmente pelas folhas, com pecíolo mais curto (1,1-1,7 vs. 2,6-3 cm compr.) e lâmina dos folíolos menor $(6-9 \times 2,8-4$ vs. $10,1-12,5 \times 4,5-6,5 \mathrm{~cm})$, e de H. altissima pelos folíolos, com lâmina maior $(6-9 \times$ $2,8-4$ vs. $4-5,7 \times 2-2,5 \mathrm{~cm}$ ) e ligeiramente falcada (vs. fortemente falcada).

4. Hymenaea eriogyne Benth., Fl. Bras. 15(2): 237. 1870.

Figuras 1D, 5 e 12E,F; Lee \& Langenheim (1975: fig. 19).

Árvore ou arbusto $1,5-12 \mathrm{~m}$ alt.; tronco $50-240 \mathrm{~cm}$ de perímetro; ramos, folhas e frutos glabros ou indumentados, tricomas translúcidos ou ferrugíneos, curtos ou moderadamente longos, eretos ou sinuosos. Pecíolo 0,2-0,5(-0,8) cm compr.; peciólulos $0,2-0,4 \mathrm{~cm}$ compr.; folíolos $2-5(-5,7) \times 1,6-2,7(-3,8) \mathrm{cm}$, obovais ou oblongos, raramente elípticos, levemente falcados, ápice arredondado, obtuso, retuso ou emarginado, base oblíqua, lado interno agudo, o externo retuso a arredondado, margem ligeira a fortemente revoluta, raramente plana, cartáceos ou coriáceos, face adaxial glabra ou levemente indumentada, a abaxial glabra ou densamente indumentada, nervuras primária $\mathrm{e}$ secundárias sutilmente visíveis na face adaxial, proeminentes na abaxial, pontuações translúcidas em toda a lâmina. Panículas (5)8-13 cm compr., congestas, mais longas que a folha adjacente; pedicelos $0,4-1,4 \mathrm{~cm}$ compr. Flores 24-36 cm compr., hipanto (7)13-15 mm compr., campanulado, base alongada (4-8 mm compr.); sépalas 14-19 × 7-9 mm, ovais, seríceo-tomentosas interna e externamente; pétalas $12-15 \times 6-7 \mathrm{~mm}$, espatuladas, unguiculadas (base ca. $7 \mathrm{~mm}$ compr.); filetes ca. $15 \mathrm{~mm}$ compr., glabrescentes, sem glândulas, anteras 7-9 mm compr.; ovário 7-9 × 2-3 mm, oblongo, densamente indumentado, estípite $2-8 \mathrm{~mm}$ compr., estilete ca. $15 \mathrm{~mm}$ compr. Frutos 9,3-10 × 2,3-3,7 $\times$ 1,1-2,5 cm, oblongos ou elípticos, cilíndricos ou lateralmente achatados, irregularmente constritos entre as sementes ou não, superfície opaca, finamente granulosa, indumentada na base ou margem lateral a totalmente indumentada, sem estrias, sutura levemente proeminente ou não. 
Endêmica do Brasil (Bahia, Ceará, Goiás, Pernambuco, Piauí, Minas Gerais e Rio Grande do Norte), ocorrendo na Caatinga e no Cerrado (Lima \& Pinto 2015). B4, C5, C6, D5, E2, E3, G5: Caatinga e Cerrado; principalmente no norte e oeste do estado. Floração: outubro a março; frutificação: dezembro a outubro.

Material selecionado - Barra, $10^{\circ} 47^{\prime} \mathrm{S}, 42^{\circ} 49^{\prime} \mathrm{W}$, out. 2000 (bot., fl.), A.T.A. Rodarte 127 (ALCB, HUEFS, HRB); Barreiras, 11 jun. 1992 (fr.), A.M. Carvalho et al. 4014 (RB); Caetité,

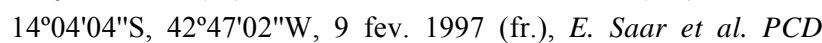
5318 (ALCB); Campo Alegre de Lourdes, 09 $29^{\prime} 06^{\prime \prime} \mathrm{S}$, $43^{\circ} 08^{\prime} 31^{\prime \prime W}, 30$ ago. 2002 (fr.), L.P. Queiroz et al. 7370 (HUEFS); Crisópolis, 29 nov. 2011 (fl.), A.M. Miranda \& J.

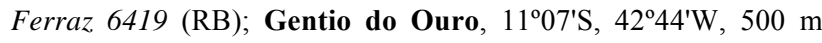
s.n.m., 24 fev. 1977 (fl.), R.M. Harley 19016 (ALCB, CEPEC, HUEFS, RB); Ibiraba, out. 1987 (est.), M.T.U. Rodrigues s.n. (SPF 81438); Pilão Arcado, 1004'30"S, 4250'13"W, 9 dez. 2005 (f1.), A.A. Conceição et al. 1560 (HUEFS); Santana, 12 ${ }^{\circ} 50^{\prime} \mathrm{S}$,

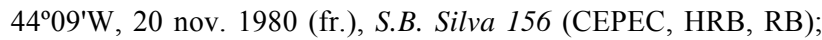
São Desidério, $12^{\circ} 21^{\prime} \mathrm{S}, 44^{\circ} 58^{\prime} \mathrm{W}, 30$ mar. 2002 (fr.), D.M.

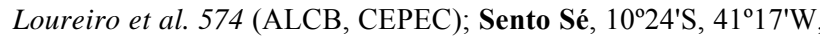
850 m s.n.m., 5 mar. 1974 (bot., fl.), R.M. Harley 16782 (CEPEC); Xique-xique, 1 jun. 1991 (fr.), H.S. Brito \& T. Pennigton 316 (CEPEC, RB).

Hymenaea eriogyne é reconhecida pelos folíolos pequenos (2-5 cm compr.), obovais ou oblongos, raramente elípticos, ápice arredondado, obtuso, retuso ou emarginado, indumentados, raramente glabros, e margem revoluta. É frequentemente confundida com $H$. aurea, diferindo pela presença de um indumento menos denso, com tricomas translúcidos ou ferrugíneos nos ramos e folíolos (vs. indumento denso, com tricomas dourados), e filetes menores (ca. $15 \mathrm{~mm}$ vs. 21-31 mm compr.). Ocorre simpatricamente a $H$. velutina, da qual distingue-se facilmente pela combinação de folhas pequenas, com pecíolo mais curto $(0,2-0,5$ vs. $1,5-2,6 \mathrm{~cm})$ e folíolos menores $(2-5$ $\times 1,6-2,7$ vs. $4,5-8 \times 2,5-5 \mathrm{~cm})$, normalmente indumentados (vs. glabros), com pontuações translúcidas em toda a lâmina (vs. restritas à margem) e lado externo da base retuso a arredondado (vs. cordado), flores com ovário indumentado (vs. glabro) e frutos sem estrias (vs. com estrias).

5. Hymenaea longifolia (Benth.) I.M.Souza, Funch \& L.P.Queiroz, PhytoKeys 38: 113. 2014.

Figuras 1E, 2A, B e 5; Lee \& Langenheim (1975: fig. 27).

Árvore (5)7-18 m alt; tronco $40-50 \mathrm{~cm}$ de perímetro; ramos glabros ou glabrescentes, tricomas translúcidos, curtos, sinuosos. Pecíolo 2,6-3 cm compr.; peciólulos $0,7-0,8 \mathrm{~cm}$ compr.; folíolos $10,1-$ $12,5(-15,4) \times 4,5-6,5(-6,9) \mathrm{cm}$, elípticos ou largoelípticos, raramente oblongos, levemente falcados, ápice agudo ou obtuso, base oblíqua, lado interno agudo ou arredondado, o externo arredondado ou ligeiramente arredondado, margem inteira, plana, coriáceos, faces adaxial e abaxial glabras ou glabrescentes, nervura primária proeminente em ambas as faces, as secundárias visíveis em ambas as faces, pontuações translúcidas em toda a lâmina. Panículas 4,9-10,3 cm compr., congestas, mais curtas que a folha adjacente; pedicelos 0,5-1,1 cm compr. Flores 26-38 $\mathrm{mm}$ compr.; hipanto 9-14 $\mathrm{mm}$ compr., campanulado, base alongada (5-7 mm compr.); sépalas 12-19 × 7-14 $\mathrm{mm}$, ovais ou largo-ovais, externamente tomentosas ou seríceo-tomentosas, internamente seríceas; pétalas 13$21 \times 5-9 \mathrm{~mm}$, ovais ou elípticas, sésseis ou subsésseis; filetes (14)16-26 mm compr., glabrescentes, sem glândulas, anteras 5-6(-9) mm compr.; ovário 6-7 × 2$3 \mathrm{~mm}$, oblongo, glabro, estípite $0-2 \mathrm{~mm}$ compr., estilete 12-20 mm compr. Frutos 11,5 $\times 4 \times 3 \mathrm{~cm}$, oblongos ou obovais, cilíndricos ou lateralmente achatados, sem constrições entre as sementes, raramente irregularmente constrito, superfície opaca, rugosa, glabra, sem estrias, sutura levemente proeminente.

Endêmica do Nordeste (Bahia, Ceará e Piauí), no Cerrado e na Caatinga (Lima \& Pinto 2015). D4, E2: Cerrado (florestas estacionais deciduais), nas regiões oeste e noroeste do estado. Floração: outubro e novembro; frutos imaturos: novembro.

Material examinado - Barra, $11^{\circ} 05^{\prime} 22^{\prime \prime} \mathrm{S}, 43^{\circ} 08^{\prime} 30^{\prime \prime} \mathrm{W}, 26$ out. 1912 (bot.), L. Zehntner 330 (RB); Barreiras, $12^{\circ} 05^{\prime} \mathrm{S}, 45^{\circ} 22^{\prime} \mathrm{W}, 12$ out. 1989 (bot., fl.), L.P. Queiroz \& N.S. Nascimento 4114 (HUEFS); Formosa do Rio Preto, $11^{\circ} 13$ 'S, 45ํㄴ' W, 14 out. 1994 (bot., fl.), L.P. Queiroz \& N.S. Nascimento 4171 (HUEFS).

Material adicional - BRASIL. CEARÁ: Brejo Santo, 9 fev. 2009 (fr.), J.G. Carvalho-Sobrinho 1925 (HUEFS). PIAUÍ: Brasileira, 8 set. 1999 (fl.), M.E. Alencar 812 (HUEFS).

Hymenaea longifolia é diagnosticada pelos folíolos grandes $(10,1-12,5 \times 4,5-6,5 \mathrm{~cm})$, elípticos ou largoelípticos, ligeiramente falcados, glabros ou

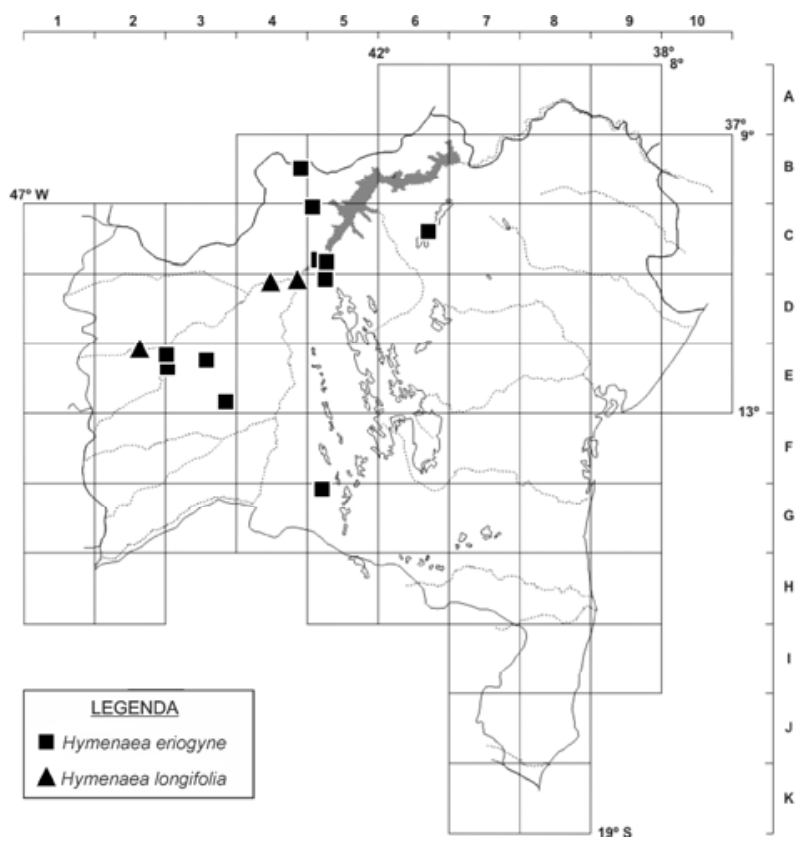

Figura 5. Distribuição geográfica de Hymenaea eriogyne e H. longifolia no estado da Bahia. 
glabrescentes, pecíolo $(2,6-3 \mathrm{~cm}$ compr.) e peciólulos (0,7-0,8 cm compr.) compridos, filetes sem glândulas e frutos normalmente sem constrições entre as sementes, com superfície opaca. Pode ocorrer simpatricamente com $H$. velutina, da qual difere pelas folhas maiores: pecíolo 2,6-3 cm compr. (vs. 1,5-2,6 cm), peciólulos $0,7-0,8 \mathrm{~cm}$ compr. (vs. 0,2-0,5 cm) e folíolos 10,1$12,5 \mathrm{~cm}$ compr. (vs. 4,5-8 cm), e com pontuações translúcidas em toda a lâmina (vs. restritas à margem da lâmina).

6. Hymenaea maranhensis Y.T.Lee \& Langenh., J. Arnold Arbor. 55(3): 441. 1974.

Figuras 1F e 6; Lee \& Langenheim (1974: fig. 2).

Árvore ou arbusto ca. $5 \mathrm{~m}$ alt.; tronco ca. $18 \mathrm{~cm}$ de perímetro; ramos e folhas indumentados, tricomas translúcidos ou dourados, curtos ou longos, eretos ou sinuosos. Pecíolo ca. 0,9 cm compr.; peciólulos 0,4$0,5 \mathrm{~cm}$ compr.; folíolos $8,1-9 \times 3,5-5,4 \mathrm{~cm}$, obovais, ápice arredondado, obtuso ou retuso, base oblíqua, lado interno agudo, o externo truncado ou arredondado, margem ligeiramente revoluta, cartáceos ou coriáceos, face adaxial levemente indumentada, a abaxial densamente indumentada, nervuras primária e secundárias visíveis na face adaxial, proeminentes na abaxial, pontuações translúcidas em toda a lâmina. Panículas $8-13 \mathrm{~cm}$ compr., congestas, mais longas que a folha adjacente; pedicelos 1,3-1,5 cm compr. Flores ca. $36 \mathrm{~mm}$ compr.; hipanto $10-15 \mathrm{~mm}$ compr., campanulado, base alongada (5-6 $\mathrm{mm}$ compr.); sépalas 22-24 × 11-13 mm, elípticas ou ovais, externamente tomentosas, internamente seríceotomentosas; pétalas $17-20 \times 6-8 \mathrm{~mm}$, espatuladas, unguiculadas (base 5-7 $\mathrm{mm}$ compr.); filetes 22-26 mm compr., glabrescentes, com glândulas, anteras 9$11 \mathrm{~mm}$ compr.; ovário $8-9 \times 2-3 \mathrm{~mm}$, oblongo, indumentado nas bordas e glabro no centro, estípite 2$4 \mathrm{~mm}$ compr., estilete ca. $17 \mathrm{~mm}$ compr. Frutos não visto.

Endêmica do Brasil, até então conhecida apenas para os estados do Maranhão e Tocantins, no Cerrado (Lima \& Pinto 2015), é registrada aqui pela primeira vez para a Bahia. E2: Cerrado, na região oeste. Floração: janeiro.

Material examinado - São Desidério, 13 jan. 2004 (bot., fl.), M. Machado \& M.V.M. Oliveira 108 (HUEFS).

Material adicional - BRASIL. MARANHÃO: Lorêto, 07 13 'S, 45 $07-08^{\prime} \mathrm{W}, 8$ abr. 1962 (bot., fl.), G. Eiten \& L. Eiten 4183 (isótipo SP).

Hymenaea maranhensis é reconhecida pelos folíolos obovais, com ápice arredondado, obtuso ou retuso, levemente indumentados na face adaxial, densamente indumentados na abaxial, flores de tamanho médio (ca. $36 \mathrm{~mm}$ compr.), pétalas espatuladas e ovário parcialmente indumentado. É facilmente confundida com $H$. stigonocarpa, a qual se distingue pelas flores maiores $(35-52 \mathrm{~mm}$ vs. ca. 36 $\mathrm{mm}$ compr.) e pétalas sésseis (vs. unguiculadas).

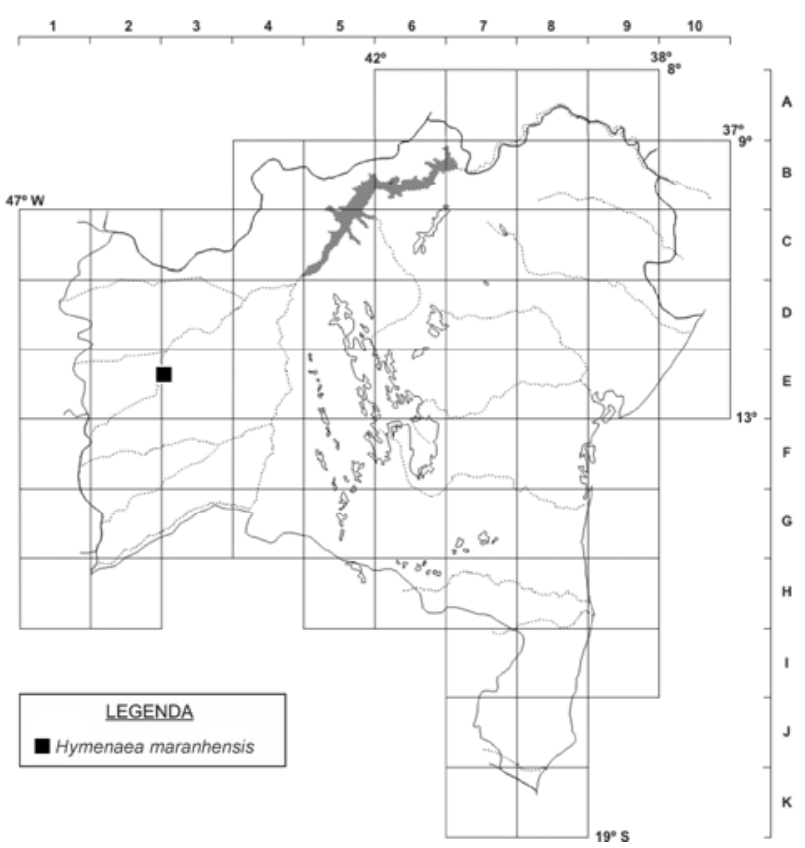

Figura 6. Distribuição geográfica de Hymenaea maranhensis no estado da Bahia.

7. Hymenaea martiana Hayne, Getreue Darstell. Gew. 11: sub pl. 15. 1830.

Figuras 1G, 7, e 11D, E; Hayne (1830: fig. 15).

Árvore $4-25 \mathrm{~m}$ alt.; tronco $20-70 \mathrm{~cm}$ de perímetro; ramos e folhas glabrescentes ou indumentados, tricomas dourados, moderadamente longos ou curtos, sinuosos. Pecíolo $(0,7) 0,9-1,3(-2,1) \quad \mathrm{cm}$ compr.; peciólulos 0,3-0,5 cm compr.; folíolos 4-7,5(-8,5) $\times$ $2-3,6(-4,6) \mathrm{cm}$, elípticos, raramente obovais, levemente falcados, ápice agudo, arredondado, obtuso ou retuso, base oblíqua, lado interno agudo, o externo retuso ou arredondado, margem plana, cartáceos ou coriáceos, face adaxial glabra a levemente indumentada, a abaxial leve a densamente indumentada, nervuras primária e secundárias sutilmente visíveis na face adaxial, proeminentes na abaxial, pontuações translúcidas em toda a lâmina. Panículas 3,7-17,5 cm compr., congestas, mais curtas que a folha adjacente, raramente mais longas; pedicelos $0,2-1,1 \mathrm{~cm}$ compr. Flores $23-31 \mathrm{~mm}$ compr.; hipanto 9-27 mm compr., campanulado, base alongada (5-15 $\mathrm{mm}$ compr.); sépalas 18-24 × 10-18 mm, ovais ou obovais, interna e externamente tomentosas ou seríceotomentosas; pétalas 16-21 × 7-14 $\mathrm{mm}$, elípticas, sésseis; filetes 16-34 mm compr., glabrescentes, com glândulas, anteras 6-9 mm compr.; ovário 5-10 × 3-4 $\mathrm{mm}$, oblongo, indumentado na base, estípite $2-5 \mathrm{~mm}$ compr., estilete 12-23 mm compr. Frutos 3,2-11,5 × 1,4-6 $\times$ 0,4-3,6 cm, oblongos, cilíndricos ou lateralmente achatados, irregularmente constritos entre as sementes, superfície opaca ou brilhante, rugosa, glabra ou levemente indumentada na base e margem lateral, sem estrias, sutura proeminente ou não.

Amplamente distribuída, com registros para a Bolívia, Brasil, Paraguai e Argentina (Ducke 1953; Lee 
\& Langenheim 1975; Killeen \& Schulenberg 1998), frequentemente associada a ambientes secos no Cerrado e na Caatinga (Lee \& Langenheim 1975). No Brasil, ocorre nas Regiões Norte (Tocantins), Nordeste (Alagoas, Bahia, Ceará, Maranhão, Pernambuco, Piauí), Centro-Oeste (Distrito Federal, Goiás, Mato Grosso do Sul, Mato Grosso) e Sudeste (Minas Gerais, São Paulo) (Lima \& Pinto 2015). B5, B7, B8, C5, C7, C9, D2, D4, D5, D6, D7, E3, E4, E5, E9, F3, F5, F6, F7, G3, G4, G5: Caatinga e Cerrado, ocorrendo em grande parte do estado. Floração: setembro a fevereiro; frutificação: novembro a agosto.

Material selecionado - Barra, $10^{\circ} 47^{\prime} 08^{\prime \prime} \mathrm{S}, 42^{\circ} 49^{\prime} 09^{\prime \prime} \mathrm{W}, 27$ out. 2000 (bot., fl.), A.T.A. Rodarte 136 (HRB, HUEFS); Barreiras, 9 nov. 1912 (fl.), L. Zehntner s.n. (RB 10902); Barro Alto, $11^{\circ} 45^{\prime} 12^{\prime \prime} \mathrm{S}, 41^{\circ} 50^{\prime} 08^{\prime \prime} \mathrm{W}, 8$ abr. 2002 (est.), T.S. Nunes et al. 922 (HUEFS); Bom Jesus da Lapa, 12 ${ }^{\circ} 58^{\prime} \mathrm{S}, 43^{\circ} 19 \mathrm{~W}, 19$ abr. 1980 (fr.), R.M. Harley 21570 (CEPEC, UEC); Caetité, 26 nov. 1992 (fl.), M.L. Guedes et al. 2884 (ALCB); Canudos, 10 abr. 1993 (fr.), M.A. Ferreira 504 (HRB, RB); Carinhanha, 14¹9'39"S, 4346'40"W, 27 nov. 2007 (fl.), M.L. Guedes et al. 14005 (ALCB,

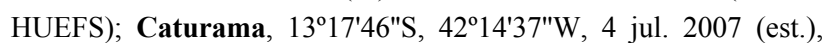

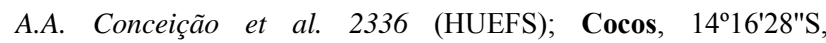
4432'55"W, 24 set. 2007 (bot.), M.L. Guedes et al. 13599 (ALCB, HUEFS); Coribe, 133' $33^{\prime \prime} \mathrm{S}, 4^{\circ} 18^{\prime} 35^{\prime \prime} \mathrm{W}, 8$ jun. 2007 (fr.), M.M.M. Lopes et al. 1360 (CEPEC, HUEFS); Dom Basílio, $13^{\circ} 43^{\prime} \mathrm{S}, 41^{\circ} 43^{\prime} \mathrm{W}, 25$ mar. 1991 (fr.), G.P. Lewis \& M.M. Andrade 1882 (CEPEC); Formosa do Rio Preto, 3 ago. 2008 (est.), B.S. Gregório 37 (BRBA); Gentio do Ouro, 10 set. 1990 (bot.), H.C.

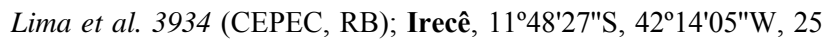
out. 2009 (bot.), F.S. Gomes et al. 323 (ALCB); Ituaçu, nov. 1988 (fl.), E. Gouvêa 16/88 (ALCB); Jequié, 15 fev. 1979 (fr.), T.S. Santos et al. 3490 (CEPEC, RB); Jeremoabo, 10¹5'22"S, 38²3'51"W, 24. jan. 2010 (fl.), T.B. Gomes 58 (HUEFS); Juazeiro, $09^{\circ} 21^{\prime} \mathrm{S}, 40^{\circ} 20^{\prime} \mathrm{W}, 21$ abr. 2007 (fr.), K.R.S. Mariano et al. 4 (CEPEC, HUEFS); Livramento do Brumado, $13^{\circ} 39^{\prime} \mathrm{S}, 41^{\circ} 50^{\prime} \mathrm{W}$, 23 mar. 1977 (fr.), R.M. Harley 19889 (RB); Macaúbas, 25 jul. 1973 (bot.), F.B. Ramalho 250 (PEUFR, RB); Marcelino Souza, 7 jul. 2009 (fr.), J.E. Meireles et al. 660 (RB); Miguel Calmon,

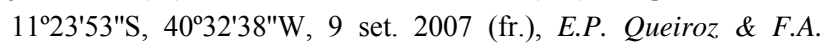

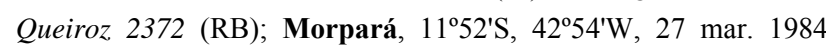
(est.), H.P. Bautista \& O.A. Salgado 883 (RB); Morro do Chapéu, 11'28'18"S, 4122'11"W, 9 mar. 2003 (fr.), L.P. Queiroz et al. 7711 (HUEFS); Mucugê, 18 jan. 2012 (fl.), I.M. Souza 89 (HUEFS). Oliveira dos Brejinhos, 12 $22^{\prime} \mathrm{S}, 42^{\circ} 54^{\prime} \mathrm{W}, 18 \mathrm{dez} .2007$ (fr.), A.A. Conceição et al. 2794 (HUEFS); Pindobaçu, 10 $40^{\circ} \mathrm{S}, 40^{\circ} 21^{\prime} \mathrm{W}, 20$ dez. 1999 (bot.), M.L. Guedes et al. 6992 (ALCB); Quixaba, $11^{\circ} 48^{\prime} \mathrm{S}, 43^{\circ} 10^{\prime} \mathrm{W}, 25$ jan. 2001 (fr.), M.L. Guedes \& D. Paulo Filho 7929 (ALCB, CEPEC); Remanso, 09²4'52"S, 42019'36"W, 24 set. 2009 (bot., fl.), F.S. Gomes 287 (ALCB, HUEFS); Rio de Contas, 9 fev. 1990 (fl.), A.M. Miranda \& F. Esteves 173 (HRB); Sento Sé, 09 $55^{\prime} 17^{\prime \prime S}, 42^{\circ} 02^{\prime} 02^{\prime \prime W}, 14$ nov. 2007 (bot.), C. Correia et al. 351 (HUEFS); Tucano, 12 01'33"S, 38 38'22"W, 5 jan. 2006 (fl.), D. Cardoso \& J.M.O. Santos 922 (HUEFS, SPF); Urandi, 1446'38"S, 42035'35"W, 4 ago. 2009 (fr.), M.L. Guedes et al. 15819 (ALCB, HUEFS); Xique-xique, 29 abr. 1999 (fr.), S.M. Faria \& H.C. Lima 1339 (RB).

Hymenaea martiana é reconhecida pelo porte arbóreo, ramos e folhas geralmente indumentados, folíolos elípticos, ligeiramente falcados, com ápice variando entre agudo, arredondado, obtuso ou retuso, e flores com pétalas sésseis e ovário com tufo de tricomas na base. É frequentemente confundida com $H$. courbaril, da qual difere pelos ramos e folíolos indumentados (vs. glabros) e ovário com tufo de tricomas na base (vs. totalmente glabro).

8. Hymenaea oblongifolia var. Iatifolia Y.T.Lee \& Langenh., J. Arnold Arbor. 54(1): 98, f. 1 e 3. 1973. Figuras 1H, 3A-F, 7 e 12A-D; Lee \& Langenheim (1973: fig. 3).

Árvore 15-35 m alt.; tronco 30-60 cm de perímetro; ramos e folhas glabros. Pecíolo 2-3,3($3,8)$ cm compr.; peciólulos 0,5-0,8 cm compr.; folíolos 9,3-19,6(-26) × 5,2-9,3(-11) cm, oblongos ou obovais, levemente falcados, ápice obtuso, acuminado ou cuspidado, base oblíqua, lado interno agudo, o externo arredondado, margem inteira, plana, cartáceos, nervuras primária e secundárias pouco visíveis na face adaxial, proeminente na abaxial, pontuações translúcidas em toda a lâmina, concentradas na margem. Panículas $14-22 \mathrm{~cm}$ compr., laxas, mais longas que a folha adjacente, tricomas dourados, curtos, sinuosos; pedicelos 0,20,4 cm compr. Flores 14-16 mm compr.; hipanto ca. $5 \mathrm{~mm}$ compr., campanulado, base alongada (1-2 mm compr.); sépalas 8-11 × 6-7,5 mm compr., largoovais, externamente tomentosas, internamente seríceo-tomentosas; pétalas 13-15 × 7-8 $\mathrm{mm}$, espatuladas, unguiculadas (base 5-7 $\mathrm{mm}$ compr.); filetes 14-23 mm compr., glabros, glândulas ausentes, anteras ca. $3 \mathrm{~mm}$ compr.; ovário 6-7 $62-4 \mathrm{~mm}$, oblongo, totalmente indumentado, hirsuto na base, estípite ca. $2 \mathrm{~mm}$ compr., estilete ca. $15 \mathrm{~mm}$ compr. Frutos 4,1-6,4 × 2,8-3,8 × 1,3-2,6 cm, orbiculares ou

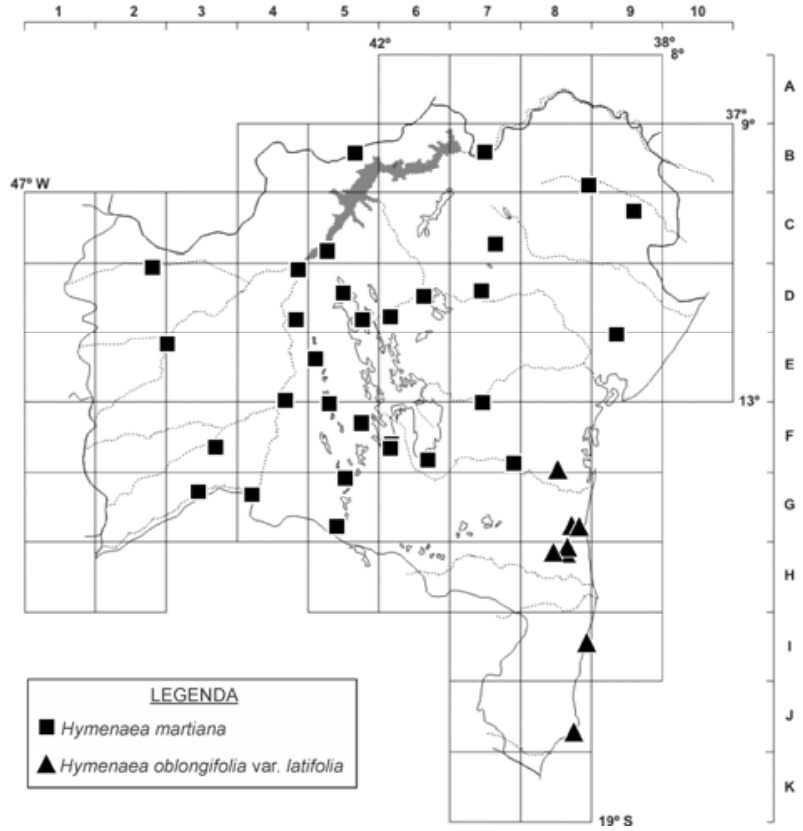

Figura 7. Distribuição geográfica de Hymenaea martiana e H. oblongifolia var. latifolia no estado da Bahia. 
obovoides, cilíndricos, sem constrições entre as sementes, superfície opaca, finamente granulosa, indumentada na base, sem estrias, sutura não proeminente.

Hymenaea oblongifolia está bem distribuída na América do Sul, com registros para a Bolívia, Brasil, Colômbia, Guiana, Guiana Francesa, Peru, Suriname (Lee \& Langenheim 1975), Equador (Neill \& Palacios 1989) e Venezuela (Langenheim 1967). No Brasil, apresenta distribuição disjunta, ocorrendo nas Regiões Norte, representada pelas variedades oblongifolia (Acre, Amazônas, Pará e Rondônia) e palustris Ducke (Y.T.Lee \& Langenh.) (Amazonas, Amapá e Pará) na Amazônia, e no Nordeste (Bahia e Pernambuco), representada pela variedade latifolia, endêmica da Mata Atlântica (Lima \& Pinto 2015). F8, G8, H8, I8, J8: Mata Atlântica (florestas ombrófilas densas), na região litorânea. Floração: janeiro; frutificação: junho a dezembro.

Material examinado - Arataca, $15^{\circ} 10^{\prime} 25^{\prime \prime} \mathrm{S}, 39^{\circ} 20^{\prime} 30^{\prime \prime} \mathrm{W}, 22$ set. 2007 (est.), F.M. Ferreira et al. 1410 (CEPEC); Caravelas, 17 $44^{\prime} 44^{\prime \prime S}, 39^{\circ} 14^{\prime} 10^{\prime \prime W}, 13$ dez. 2011 (fr.), E.N. Matos et al. 993 (HUEFS); Ibirapitanga, $13^{\circ} 58^{\prime} \mathrm{S}, 39^{\circ} 28^{\prime} \mathrm{W}, 16$ jan. 201 (bot., fl.), I.M. Souza 160 (HUEFS); Ilhéus, 14²4'35"S, 39¹0'24"W, 29 jan. 2008 (bot., fl.), L.A. Mattos Silva \& B.R. Santos 5053 (ALCB, CEPEC, HUESC); Itabuna, 2 ago. 1972 (fr.), R.S. Pinheiro 1932 (CEPEC); Jussari, 1509'37"S, 39³2'10"W, fev. 2004 (est.), P. Fiaschi et al. 1933 (CEPEC); Porto Seguro, 16²6'59"S, 3903'53"W, 12 nov. 1999 (fr.), E.J. Leite et al. 47 (CENARGEN); São José, 29 jan. 1971 (bot., fl.), T.S. Santos 1447 (CEPEC).

Hymenaea oblongifolia var. latifolia caracteriza-se pelos ramos e folhas glabros, folíolos marcadamente oblongos ou obovais, inflorescências laxas, flores pequenas (14-16 $\mathrm{mm}$ compr.), com pétalas espatuladas e ovário totalmente indumentado, e frutos pequenos $(4,1-6,4 \mathrm{~cm}$ compr.), geralmente orbiculares, com superfície levemente indumentada na base. É o único representante da seção Trachylobium no Nordeste (Lee \& Langenheim 1975). A espécie ocorre simpatricamente com $H$. aurea e $H$. altissima, diferindo destas espécies principalmente pelos folíolos maiores $(9,3-19,6 \mathrm{~cm}$ vs. 4-7,5 cm compr.) e as flores pequenas (14-16 mm vs. 20-37 mm compr.). Além disso, H. oblongifolia var. latifolia tem ramos e folhas glabros (vs. densamente indumentados), diferente de $H$. aurea, e folíolos levemente falcados (vs. fortemente falcados), pétalas unguiculadas (vs. sésseis) e ovário indumentado (vs. glabro), diferente de H. altissima.

9. Hymenaea rubriflora Ducke var. rubriflora, Mem. Inst. Oswaldo Cruz 51: 457. 1953.

Figuras 1I e 8; Lee \& Langenheim (1975: fig. 22A-H).

Árvore ou arbusto 3-8 m alt.; ramos, folhas e inflorescências indumentados, tricomas ferrugíneos, curtos, eretos ou sinuosos. Pecíolo ca. $0,8 \mathrm{~cm}$ compr.; peciólulos ca. 0,5 cm compr.; folíolos 9,1-12 × 4,3-5,2 $\mathrm{cm}$, obovais, raramente oblongos, levemente falcados, ápice obtuso ou arredondado, base oblíqua, o interno agudo, lado externo levemente arredondado ou retuso, margem fortemente revoluta, coriáceos, face adaxial glabra ou esparsamente indumentada, a abaxial densamente indumentada, nervuras primária e secundárias visíveis na face adaxial, proeminentes na abaxial, pontuações translúcidas em toda a lâmina. Panículas 3-5,4(-11,4) cm compr., congestas, mais curtas que a folha adjacente, raramente mais longas; pedicelos $0,1-0,3 \mathrm{~cm}$ compr. Flores 22-30 $\mathrm{mm}$ compr.; hipanto ca. 0,6 mm compr., campanulado, base não alongada; sépalas 11-14 × 6-9 mm, obovais ou oblongas, interna e externamente seríceas; pétalas 9-10 $\times$ 5-6 mm, elípticas, subsésseis (base ca. 0,5 $\mathrm{mm}$ compr.), glabras; filetes 14-16 mm compr., glabros, com glândulas, anteras 4-5 mm compr.; ovário ca. 8$10 \times 2-3 \mathrm{~mm}$, oblongo, glabro, estípite $2-3 \mathrm{~mm}$ compr., estilete ca. $30 \mathrm{~mm}$ compr. Frutos ca. $6,3 \times 2,3$ $\mathrm{cm}$, oblongos, lateralmente achatados, sem constrições entre as sementes, superfície brilhante, rugosa, glabra, sem estrias, sutura proeminente.

Endêmica do Nordeste do Brasil (Alagoas, Paraíba, Pernambuco e Rio Grande do Norte), na Mata Atlântica (Lima \& Pinto 2015). É registrada pela primeira vez para o sul da Bahia. H9: Mata Atlântica (floresta ombrófila densa). Floração: abril

Material examinado - Belmonte, $15^{\circ} 51^{\prime} 47^{\prime \prime} \mathrm{S}, 38^{\circ} 52^{\prime} 58^{\prime \prime} \mathrm{W}, 24$ abr. 1972 (bot., fl.), M.T. Monteiro 22700 (IPA).

Material adicional - BRASIL. PARAÍBA: João Pessoa, 16 abr. 1967 (bot., fl., fr.), D. Andrade-Lima 4988 (IPA). PERNAMBUCO: Aliança, 4 fev. 1971 (bot., fl.), P. Ferreira 71 (IPA); Igarassu, 1 abr. 1962 (bot., fl.), D. Andrade-Lima 62-4045 (IPA).

Hymenaea rubriflora var. rubriflora é caracterizada pelos folíolos coriáceos, geralmente obovais, face adaxial glabra ou esparsamente indumentada, brilhante, face abaxial densamente indumentada, margem fortemente revoluta, e flores com pétalas sésseis, usualmente avermelhadas. No entanto, algumas populações podem apresentar flores com pétalas creme, como verificado no espécime encontrado na Bahia e também documentado por Lee \& Langenheim (1975). Hymenaea rubriflora possui uma segunda variedade, $H$. rubriflora var. glabra Y.T.Lee \& Langenh., a qual apresenta poucas coletas e distribuição restrita à Paraíba e Sergipe, (Lima \& Pinto 2015), diferindo da variedade típica pelos folíolos glabros, mais largos e menos coriáceos (Lee \& Langenheim 1975). Em relação aos demais representantes de Hymenaea da Mata Atlântica, difere de $H$. aurea pelo indumento composto de tricomas ferrugíneos e curtos (vs. dourados e longos) e pétalas subsésseis (vs. unguiculadas); de $H$. oblongifolia var. latifolia, pelos folíolos indumentados (vs. glabros) com margem revoluta (vs. inteira), inflorescências congestas (vs. laxas), flores maiores (22-30 mm vs. 14-16 mm compr.) e pétalas subsésseis (vs. unguiculadas); e de $H$. altissima, pelos folíolos obovais (vs. ovais, estreito-elípticos ou elípticos) e indumentados (vs. glabros). 


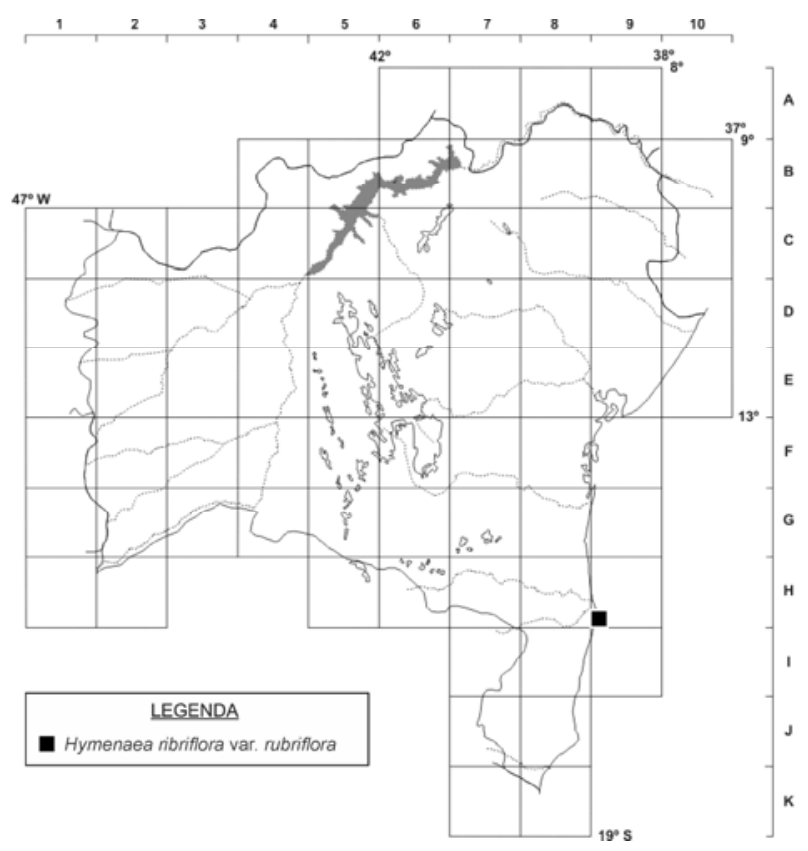

Figura 8. Distribuição geográfica de H. rubriflora var. rubriflora no estado da Bahia

10. Hymenaea stigonocarpa Mart. ex Hayne, Getreue Darstell. Gew. 11: sub pl. 13. 1830.

Árvore ou arbusto 1,5-8(-15) m alt.; tronco 20$28,5 \mathrm{~cm}$ de perímetro; ramos e folhas glabros ou indumentados, inflorescências indumentadas, tricomas translúcidos, curtos ou moderadamente longos, sinuosos ou eretos. Pecíolo $1-4(-4,8) \mathrm{cm}$ compr.; peciólulos $0,5-0,8 \mathrm{~cm}$ compr.; folíolos (5)8-17,5 $(29,5) \times(4) 4,6-9(-10) \mathrm{cm}$, obovais ou largo-elípticos, falcados, ápice obtuso ou arredondado, raramente agudo, base oblíqua, lado interno agudo ou levemente arredondado, o externo moderado a fortemente arredondado, margem plana, cartáceos ou coriáceos, face adaxial glabra a levemente indumentada, a abaxial glabra a densamente indumentada, nervuras primária e secundárias visíveis a sutilmente pronunciadas na face adaxial, proeminentes na abaxial, pontuações translúcidas em toda lâmina. Panículas 4,8-15,1 cm compr., congestas, mais curtas que a folha adjacente, raramente mais longas; pedicelos 0,5-1,6 cm compr. Flores 35-52 cm compr.; hipanto 5-14 mm compr., obcônico, base alongada (1-5 mm compr.) ou não; sépalas $24-27 \times 17-21 \mathrm{~mm}$, ovais a largo-ovais, externamente tomentosas, internamente seríceas ou seríceo-tomentosas; pétalas 23-28 × 13-19 mm, elípticas ou obovais, sésseis; filetes 35-44 mm compr., glabrescentes, com glândulas, anteras ca. $8 \mathrm{~mm}$ compr.; ovário 10-11 $\times 5 \mathrm{~mm}$, oblongo, glabro ou levemente indumentado na margem lateral, estípite 3-5 mm compr., estilete 16-26 mm compr. Frutos 9,2$14,2 \times 3,5-4,7 \times 1,6-3,4 \mathrm{~cm}$, oblongos, cilíndricos ou lateralmente achatados, sem constrições entre as sementes, superfície brilhante, rugosa, glabra, estrias ausentes, sutura proeminente.
Espécie típica do Cerrado, com registros para Bolívia (Mamani et al. 2010; 2011), Brasil e Paraguai (Lee \& Langenheim 1975). No Brasil, apresenta-se amplamente distribuída, sendo encontrada nas Regiões Centro-Oeste (Distrito Federal, Goiás, Mato Grosso do Sul, Mato Grosso), Nordeste (Bahia, Ceará, Maranhão), Norte e Sudeste (Minas Gerais, São Paulo), na Amazônia, Caatinga, Cerrado e Pantanal (Lima \& Pinto 2015). C2, C9, D4, D7, E2, E5, E6, F2, F4, F5, F6, G3, G4, G5: Cerrado e Caatinga, estando amplamente distribuída no centro e no oeste do estado. Floração: dezembro a abril; frutificação: abril a setembro, com frutos maduros até dezembro.

Hymenaea stigonocarpa é facilmente diagnosticada pelo hábito arbustivo ou arbóreo de pequeno porte, com tronco retorcido e periderme descamante, folíolos geralmente obovais, com lado externo da base arredondado, se aproximando ou tocando o ramo, flores grandes (35-52 $\mathrm{mm}$ compr.), hipanto frequentemente obcônico, séssil, pétalas sésseis e ovário glabro, raramente apresentando indumento na margem lateral. $\mathrm{Na}$ revisão do gênero, foram reconhecidas três variedades para a espécie: $H$. stigonocarpa var. brevipetiolata N.F.Mattos, $H$. stigonocarpa var. pubescens e $H$. stigonocarpa var. stigonocarpa (Lee \& Langenheim 1975). A espécie pode ocorrer simpatricamente com $H$. martiana, $H$. courbaril e $H$. velutina, diferindo das duas primeiras principalmente pelos folíolos geralmente obovais ou largo-elípticos (vs. elípticos), bem maiores $(8-13 \mathrm{~cm}$ vs. 4-9 cm compr.), com lado externo da base fortemente arredondado (vs. ligeiramente arredondado), e da última (H. velutina) principalmente pelos ramos e folíolos usualmente indumentados (vs. sempre glabros), com pontuações translúcidas em toda a lâmina (vs. restritas a borda da lâmina). Sua semelhança com $H$. maranhensis tem gerado frequentes equívocos na identificação de materiais herborizados quando a separação é feita principalmente pelo formato das pétalas e o indumento do ovário. No entanto, $H$. stigonocarpa ainda difere de $H$. maranhensis pelo pecíolo $(1,5-2,2 \mathrm{~cm}$ vs. ca. $0,9 \mathrm{~cm}$ compr.) e peciólulos $(0,5-0,8 \mathrm{~cm}$ vs. $0,4-0,5 \mathrm{~cm}$ compr.) mais longos e pela margem dos folíolos plana (vs. ligeiramente revoluta).

\subsection{Hymenaea stigonocarpa var. pubescens Benth.,} Fl. Bras. 15(2): 236. 1870.

Figuras 1L e 9; Lee \& Langenheim (1975: fig. 32F-H). É caracterizada pelos ramos densamente indumentados, pecíolo $(2) 2,5-4(-4,8) \mathrm{cm}$ compr., e folíolos 12,5-17,5(-29,5) × 7-9(-9,8) cm. Assim como na variedade típica, as características das flores e frutos são mantidas. Apresenta distribuição geográfica mais restrita ao Cerrado, sendo encontrada no oeste da Bahia.

Material selecionado - Barreiras, 4 jun. 1991 (fr.), H.S. Brito \& T. Pennigton 344 (CEPEC, RB); Formosa do Rio Preto, 
$11^{\circ} 07^{\prime} \mathrm{S}, 45^{\circ} 28^{\prime} \mathrm{W}, 7$ abr. 1989 (fl., fr.), B.M.T. Walter et al. 221 (IBGE, RB).

Material adicional - BRASIL. GOIÁS: Cavalcanti, 13 abr. 2008 (bot.), G. Martinelli 16397 (HUEFS); Formosa, 15¹1'31"S, 47028'33"W, 15 abr. 2005 (fr.), L.P. Queiroz et al. 10296 (HUEFS); Niquelândia, 13 abr. 1992 (fl.), B.M.T. Walter et al. 1248 (HUEFS); PIAUÍ: Guadalupe, 2 jun. 2005 (fr.), I.C. Nascimento Júnior et al. 361 (UB). MATO GROSSO: Xavantina, 7 out. 1968 (fr.), R.M. Harley 10531 (UB).

\subsection{Hymenaea stigonocarpa var. stigonocarpa}

Figuras 1K, 9 e 13A-C; Lee \& Langenheim (1975: fig. $32 \mathrm{~A}-\mathrm{E})$.

Caracterizada pelos ramos geralmente glabros, pecíolo 1-2,2(-2,8) cm compr., glabro ou indumentado, e folíolos (5)8-13 × (4)4,6-7 cm. As flores e frutos são como na descrição da espécie. Apresenta ampla distribuição geográfica, ocorrendo preferencialmente no Cerrado, sendo encontrada também na Caatinga, incluindo os campos rupestres.

Material selecionado - Abaíra, $1^{\circ}{ }^{\circ} 18^{\prime} \mathrm{S}, 4^{\circ}{ }^{\circ} 51^{\prime} \mathrm{W}, 2$ mar. 1992 (fl.), B. Stannard et al. 51706 (HUEFS, RB, SPF); Andaraí, 1251'S, 41ํ12'W, 13 fev. 1977 (bot.), R.M. Harley 18644 (CEPEC); Barra, 15 jun. 1994 (fr.), L.P. Queiroz \& N.S. Nascimento 3937 (HUEFS); Bom Jesus da Lapa, 6 abr. 1992 (fr.), S.M. Faria et. al.

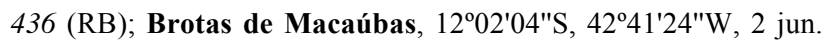
2007 (fr.), A.A. Conceição 2204 (HUEFS); Caetité, 14 05'19"S, 42³0'19"W, 28 abr. 2003 (fr.), M.L. Guedes et al. 10313 (CEPEC,

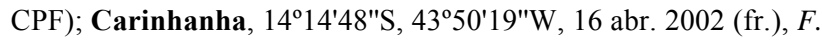

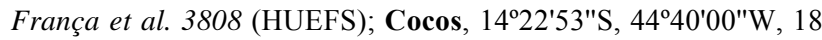
jul. 2007 (est.), M.L. Guedes \& M.L. Valadão 13636 (HUEFS); Correntina, 27 jul. 1989 (fr.), B.J. Dias et al. 21 (IBGE, UB);

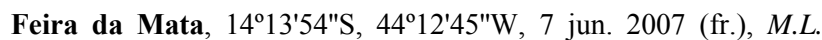

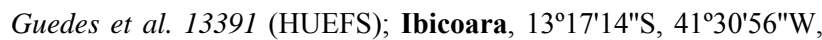
mar. 2008 (bot., f1.), S.F. Conceição \& T.R.S. Silva 648 (HUEFS); Igaporã, 135' $48^{\circ} \mathrm{S}, 42^{\circ} 33^{\prime} 57^{\prime \prime} \mathrm{W}, 15$ maio 2001 (fr.), M. Groppo

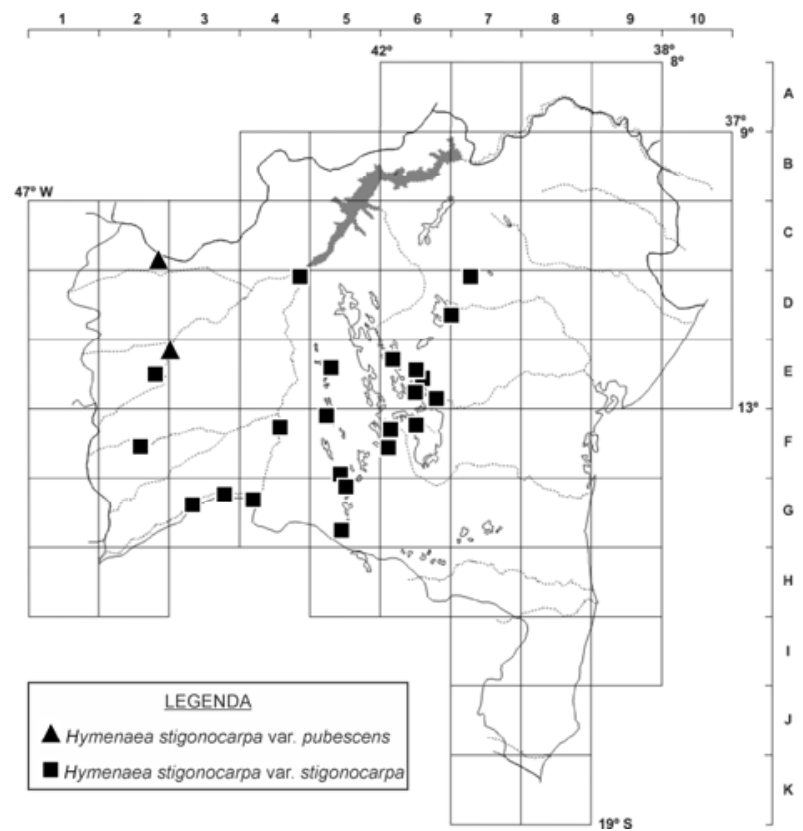

Figura 9. Distribuição geográfica de $H$. stigonocarpa var. pubescens e Hymenaea stigonocarpa var. stigonocarpa no estado da Bahia.
Jr. et al. 733 (HUEFS); Jacobina, 20 fev. 1993 (bot., fl.), A.M.V. Carvalho et al. 4155 (CEPEC, RB); Lençóis, 12²7'51"S, 41 $25^{\prime} 05^{\prime \prime} \mathrm{W}, 26$ out. 2014 (est.), L.P. Queiroz 15992 (HUEFS); Licínio de Almeida, 11 jan. 2011 (bot.), F.A. Santana 18 (HUEFS); Macaúbas, $13^{\circ} 05^{\prime} 10^{\prime \prime} \mathrm{S}, 42^{\circ} 45^{\prime} 12^{\prime \prime} \mathrm{W}, 7$ jul. 2007 (fr.), A.A. Conceição et al. 2502 (HUEFS); Morro do Chapéu, 11³7'52"S, 405' $20^{\prime \prime} \mathrm{W}, 9$ mar. 2003 (fl., fr.), L.P. Queiroz 7700 (CEPEC, HUEFS); Mucugê, 12051'45"S, 41¹7'44"W, 12 mar. 2008 (fr.), L.P. Queiroz et al. 13623 (HUEFS); Palmeiras, 21 jan. 2012 (bot.), I.M. Souza 95 (HUEFS); Piatã, 1314'33"S, 414'33"W, 23 dez. 2012 (bot.), I.M. Souza \& A. Moura 144 (HUEFS); Ribeira do Pombal, $10^{\circ} 50^{\prime} 04^{\prime \prime} \mathrm{S}, 38^{\circ} 32^{\prime} 09^{\prime \prime} \mathrm{W}, 28$ ago. 1996 (est.), L.P. Queiroz \& N.S. Nascimento 4652 (HUEFS); Rio de Contas, 133' $15^{\prime \prime} \mathrm{S}, 41^{\circ} 47^{\prime} 08^{\prime \prime} \mathrm{W}$ 30 jun. 1978 (fr.), A.P. Araújo 49 (CEPEC); São Desidério, 12³6'S, 4451'W, 1 jul. 2001 (fr.), D.L. Santana et al. 462 (CEPEC); Seabra, $12^{\circ} 17^{\prime} 03^{\prime \prime S}, 41^{\circ} 48^{\prime} 57^{\prime \prime} \mathrm{W}, 22$ jul. 1993 (fr.), L.P. Queiroz \& N.S. Nascimento 3373 (HUEFS); Urandi, 144 $44^{\prime} 50^{\prime \prime} \mathrm{S}, 4^{\circ} 34^{\prime} 27^{\prime \prime} \mathrm{W}, 31$ mar. 2001 (fr.), J.G. Jardim et al. 3324 (CEPEC, HUEFS).

11. Hymenaea velutina Ducke, Arch. Jard. Bot. Rio de Janeiro 4: 48. 1925.

Figuras 1J, 2C, D e 13D-F; Lee \& Langenheim (1975: fig. 30).

Árvore ou arbusto $(0,8) 2-25 \mathrm{~m}$ alt.; tronco ca. 50 $\mathrm{cm}$ de perímetro; ramos e folhas glabros. Pecíolo (1,1)1,5-2,6 cm compr.; peciólulos $0,2-0,5 \mathrm{~cm}$ compr.; folíolos 4,5-8(-10,5) × 2,5-5(-5,6) cm, oblongos ou obovais, raramente largo-elípticos, levemente falcados, ápice arredondado, obtuso ou retuso, raramente agudo, base oblíqua, lado interno arredondado, o externo cordado, margem plana, papiráceos ou coriáceos, nervura primária proeminente em ambas as faces, as secundárias proeminentes na face adaxial, pontuações restritas à margem da lâmina, raramente no entorno das nervuras primária e secundária. Panículas $8,1-15 \mathrm{~cm}$ compr., congestas, mais longas que a folha adjacente, raramente mais curtas, indumentadas, tricomas ferrugíneos, curtos, eretos; pedicelos $0,4-0,9 \mathrm{~cm}$ compr. Flores 25-37 mm compr.; hipanto $12-18 \mathrm{~mm}$ compr., campanulado, base alongada $(5-11 \mathrm{~mm}$ compr.); sépalas 20-24 × 9-16 mm, obovais a largoelípticas, externamente velutinas, internamente seríceotomentosas; pétalas 20-27 × 9-12 mm, espatuladas, unguiculadas (base 4-7 mm compr.); filetes $27-49 \mathrm{~mm}$ compr., glabros, sem glândulas, anteras 6-7 mm compr.; ovário 7-8 $\times 2-3 \mathrm{~mm}$, oblongo, glabro, estípite 3-5 mm compr., estilete 21-22 mm compr. Frutos $7,5-16,8 \times 2,6-6,3 \times 1,1-3,2 \mathrm{~cm}$, oblongos ou elípticos, cilíndricos ou lateralmente achatados, irregularmente constritos entre as sementes ou não, superfície opaca, finamente granulosa, glabra, com estrias, sutura proeminente ou não.

Endêmica do Nordeste (Alagoas, Bahia, Ceará, Maranhão e Piauí), na Caatinga e no Cerrado (Lima \& Pinto 2015). Na Bahia, ocorre exclusivamente no norte e oeste do estado, principalmente sobre solo arenoso. B4, B6, C2, D3, D4, D5: Caatinga e Cerrado. Floração: junho a novembro; frutificação: setembro a abril. 


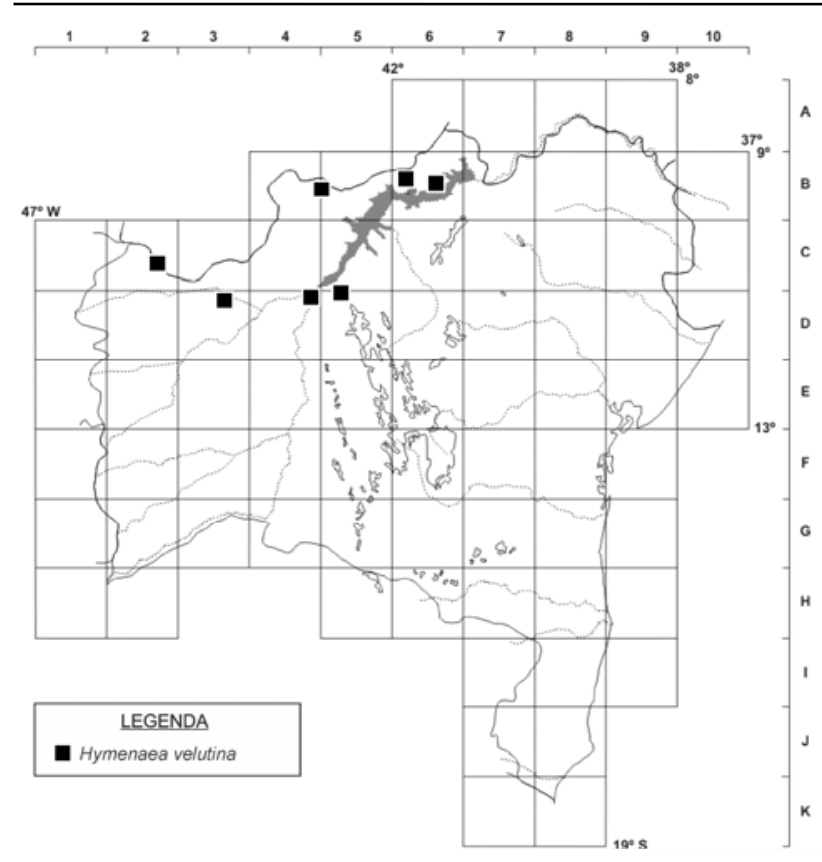

Figura 10. Distribuição geográfica de $H$. velutina no estado da Bahia.

Material selecionado: Campo Alegre de Lourdes, 09²32'06"S, 42 59 '22"W, 24 nov. 2003 (bot., fl., fr.), L.P. Queiroz et al. 8040 (HUEFS); Casa Nova, 09²2'34"S, 4148'26"W, 1 set. 2002 (bot., fl.), L.P. Queiroz et al. 7404 (ALCB, HUEFS); Formosa do Rio Preto, $10^{\circ} 36^{\prime} 37^{\prime \prime S}, 45^{\circ} 17^{\prime} 00^{\prime \prime} \mathrm{W}, 28$ mar. 2000 (fr.), R.M. Harley et al. 53775 (ALCB, CEPEC); Gentio do Ouro, $11^{\circ} 01^{\prime} \mathrm{S}, 42^{\circ} 43^{\prime} \mathrm{W}, 19$ jan. 1997 (fl.), M.M. Arbo et al. 7482 (CEPEC, RB); Remanso, 09 $26^{\prime} 22^{\prime \prime S}, 41^{\circ} 22^{\prime} 47^{\prime \prime} \mathrm{W}, 27$ nov. 2003 (fl., fr.), L.P. Queiroz et al. 7994 (HUEFS); Xique-xique, $11^{\circ} 07^{\prime} 42^{\prime \prime S}, 44^{\circ} 21^{\prime} 08^{\prime \prime} \mathrm{W}, 30$ jun. 2008 (fr.), A.A. Conceição et al. 2902 (HUEFS).

A espécie é diagnosticada pelos ramos e folhas glabros, pecíolos longos (1,5-2,6 cm compr.), folíolos geralmente oblongos ou obovais com ápice normalmente arredondado, obtuso ou retuso e lado externo da base cordado, flores com pétalas espatuladas, ovário glabro, e frutos oblongos ou elipsoides, com superfície opaca e estriada. Hymenaea velutina apresenta relação mais estreita com $H$. martiana e $H$. stigonocarpa (Lee \& Langenhaim 1975), com as quais ainda pode ocorrer simpatricamente, diferindo delas basicamente pelos ramos e folíolos glabros (vs. indumentados) e pontuações translúcidas restritas à borda dos folíolos (vs. uniformemente distribuídas).

\section{AgRADECIMENTOS}

À CAPES pela bolsa de Mestrado concedida a IMS; ao CNPq pela bolsa de produtividade concedida a LPQ (CNPq-Pq1C); ao Programa de Pesquisa em Biodiversidade do Semi-árido (PPBIO), ao Sistema Nacional de Pesquisa em Biodiversidade (SISBIOTA, processos CNPq 563084/2010-3 e FAPESB PES0053/2011), ao Programa de Capacitação em
Taxonomia (PROTAX, CNPq processo 562354/20107), à FAPESB (APR0162/2007) e ao projeto Flora da Bahia (483909/2012-4) pelo auxílio financeiro; e a UEFS pela infraestrutura fornecida.

\section{REFERÊNCIAS}

Aquino, F.G.; Ribeiro, J.F. \& Walter, B.M.T. 2007. Espécies vegetais de uso múltiplo em reservas legais de Cerrado, Balsas/MA. Revista Brasileira de Biociências 5(1): 147-149.

Asquith, N.M.; Terborgh, J.; Arnold, A.E. \& Riveros, C.M. 1999. The fruits the agouti ate: Hymenaea courbaril seed fate when its disperser is absent. Journal of Tropical Ecology 15: 229-235.

De Candolle, A.P. 1825. The leguminous seed. Phytomorphology 1: $117-150$.

Ducke, A. 1953. Phytogeographical notes on the Brazilian Amazon. Anais da Academia Brasileira de Ciências 24(1): 1-46.

Fabaceae in Flora do Brasil 2020 em construção. Jardim Botânico do Rio de Janeiro. Disponível em <http://reflora.jbrj.gov.br/ reflora/floradobrasil/FB115>. Acesso em 28 out. 2016

Fougère-Danezan, M.; Herendeen, P.S.; Maumont, S. \& Bruneau, A. 2010. Morphological evolution in the variable resin-producing Detarieae (Fabaceae): Do morphological characters retain a phylogenetic signal? Annals of Botany 105: 311-325.

Gibbs, P.E.; Oliveira, P.E. \& Bianchi, M.B. 1999. Postzygotic control of selfing in Hymenaea stigonocarpa (LeguminosaeCaesalpinioideae), a bat-pollinated tree of the Brazilian cerrados. International Journal of Plant Science 160: 72-78.

Killeen, T.J. \& Schulenberg, T.S. 1998. A Biological Assessment of Parque Nacional Noel Kempff Mercado, Bolivia. RAP Working Papers 10. Conservation International, Washington, D.C.

Langenheim, J.H. 1967. Preliminary investigations of Hymenaea courbaril as a resin producer. Journal Arnold Arboretum 48: 203-230.

Langenheim, J.H. 1969. Amber: a botanical inquiry. Science 163: 1157-1169.

Lee, Y.T. \& Langenheim, J.H. 1973. New taxa from Brazil and Guyana in the genus Hymenaea (Leguminosae, Caesalpinioideae). Journal Arnold Arboretum 54(1): 94-104.

Lee, Y.T. \& Langenheim, J.H. 1974. Additional new taxa and combinations in Hymenaea (Leguminosae, Caesalpinioideae). Journal Arnold Arboretum 55(1): 441-452.

Lee, Y.T. \& Langenheim, J.H. 1975. Systematics of the genus Hymenaea L. (Leguminosae; Caesalpinioideae; Detarieae). University of California Publications in Botany 69: 1-109.

Lewis, G.; Schrire, B.; Mackinder, B. \& Lock, M. 2005. Legumes of the World. Kew Royal Botanic Gardens, Kew.

Lima, H.C. \& Pinto, R.B. Hymenaea. In: Lista de Espécies da Flora do Brasil. Jardim Botânico do Rio de Janeiro. Disponível em http://floradobrasil.jbrj.gov.br/jabot/floradobrasil/FB22971. Acesso em 10 out. 2015.

Mackinder, B. 2005. Detarieae. In: G. Lewis, B. Schrire, B. MacKinder \& M. Lock (eds), Legumes of the World. The Royal Botanical Gardens, Kew, p. 69-71.

Mamani, F.; Pozo, P.; Soto, D.; Villarroel, D. \& Wood, J.R.I. 2010. Libro Rojo de las Plantas de los Cerrados del Oriente Boliviano. Darwin Initiative, Santa Cruz. 


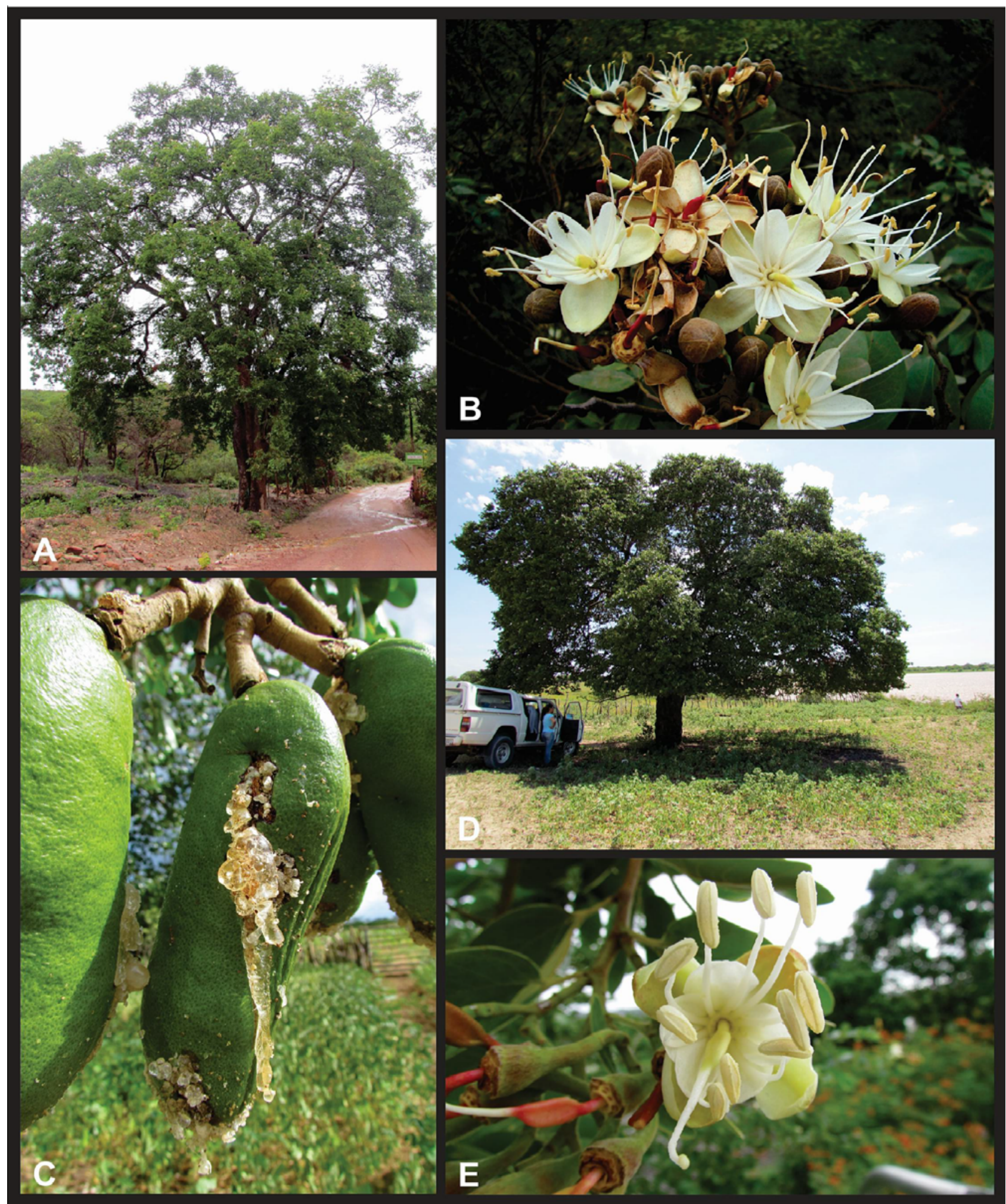

Figura 11. A-C. Hymenaea courbaril: A- hábito; B- inflorescência com botões florais e flores abertas; C- fruto imaturo (com resina). D, E. Hymenaea martiana: D- hábito; E- flor. (Fotos: I.M. Souza).

Mamani, F.; Pozo, P.; Soto, D.; Villarroel, D. \& Wood, J.R.I. 2011. Guía Darwin de las Plantas de los Cerrados de la Chiquitania. Darwin Initiative, Santa Cruz.

Neill, D.A. \& Palacios, W.A. 1989. Arboles de la Amazonia Ecuatoriana: lista preliminar de espécies. Dirección Nacional Florestal, Quito.
Pestana, L.T.C. 2010. Estudo Taxonômico de Hymenaea L.: complexo H. courbaril, H. martiana $e$ H. stigonocarpa (Fabaceae: Caesalpinioideae: Detarieae). Dissertação de Mestrado. Fundação Universidade Federal de Mato Grosso do Sul.

Queiroz, L.P. 2009. Leguminosas da Caatinga. Universidade Estadual de Feira de Santana, Feira de Santana. 


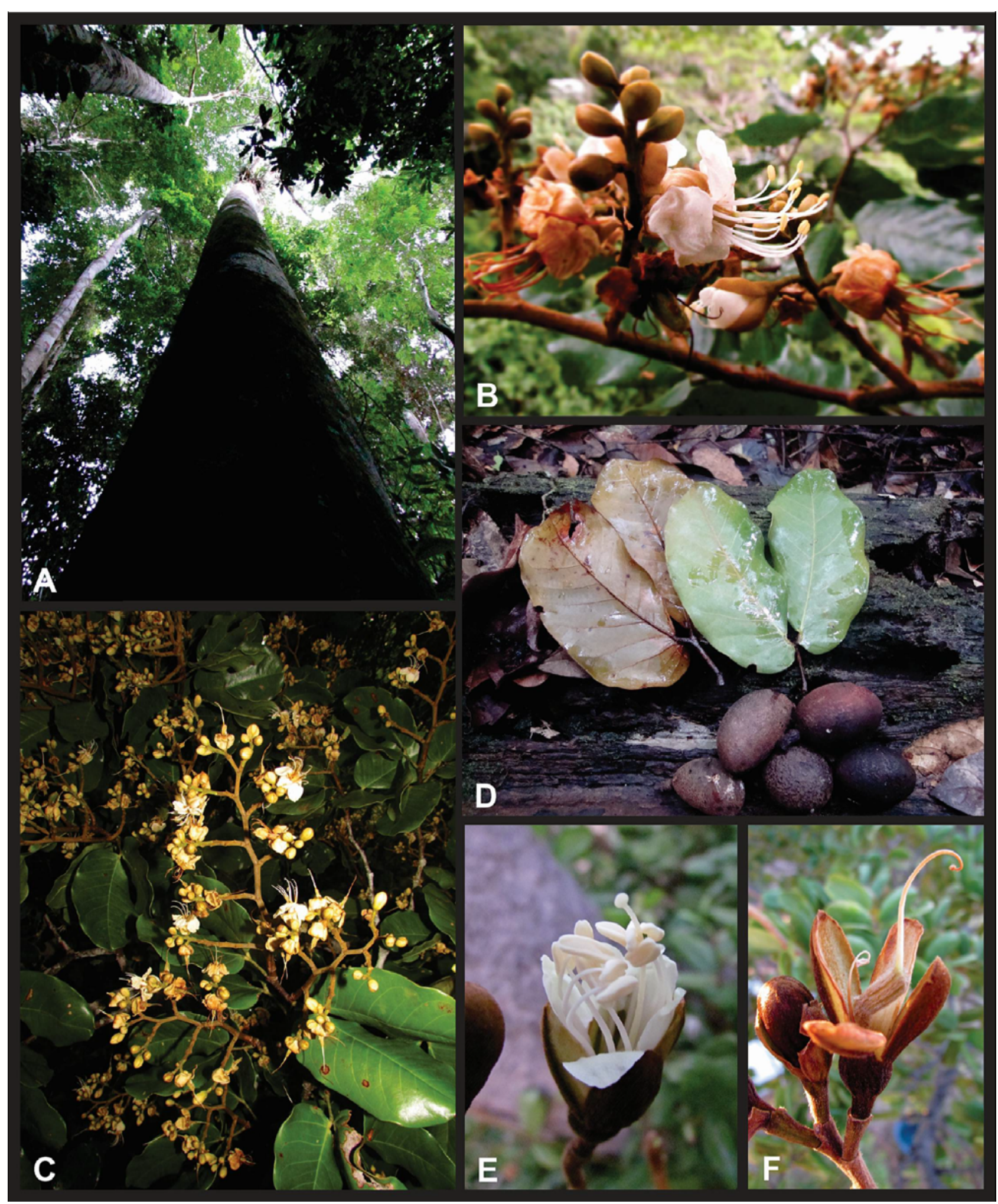

Figura 12. A-D. Hymenaea oblongifolia var. latifolia: A- hábito; B- botões florais e flor aberta; C- inflorescência; D- folhas (faces abaxial e adaxial) e frutos. E, F. Hymenaea eriogyne: E- flor em antese; F- flor senescente mostrando o ovário indumentado. (Fotos: I.M. Souza).

Ribeiro, R.D.; Cardoso, D.B.O.S. \& Lima, H.C. 2015. A new species of Hymenaea (Leguminosae: Caesalpinioideae) with a revised identification key to the genus in the Brazilian Atlantic Forest. Systematic Botany 40(1): 151-156.

Souza, I.M. 2013. O gênero Hymenaea L. (Leguminosae: Caesalpinioideae) para o estado da Bahia: aspectos sobre a taxonomia, fenologia e biologia floral. Dissertação de Mestrado. Universidade Estadual de Feira de Santana.

Souza, I.M.; Funch, L.S. \& Queiroz, L.P. 2014. Morphological analyses suggest a new taxonomic circumscription for Hymenaea courbaril L. (Leguminosae, Caesalpinioideae). PhytoKeys 38: 101-18. 


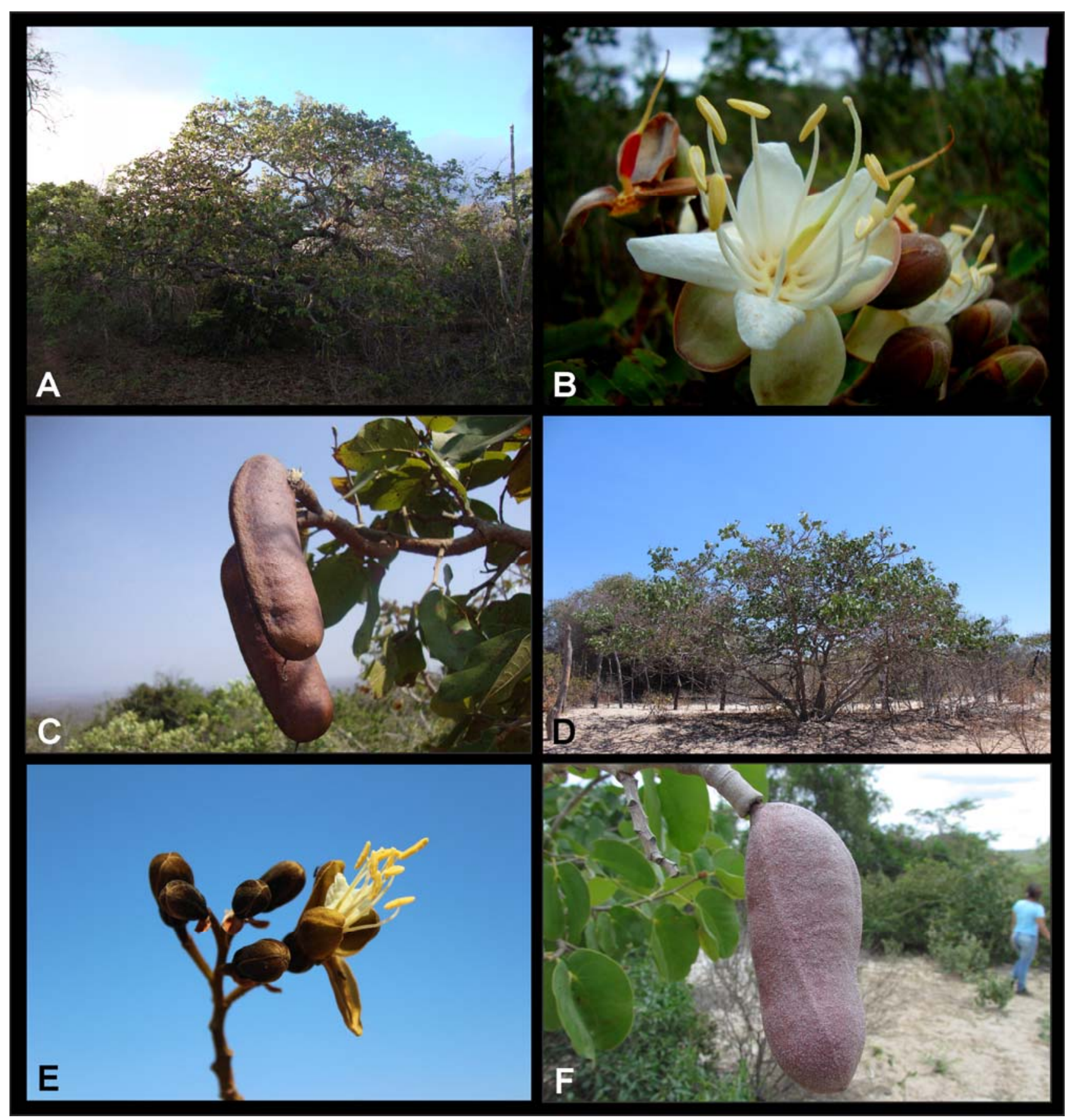

Figura 13. A-C. Hymenaea stigonocarpa var. stigonocarpa: A- hábito; B- flor; C- fruto. D-F. Hymenaea velutina: D- hábito; E- inflorescência com botões e uma flor aberta; F- fruto. (Fotos: I.M. Souza)

\section{LISTA DE EXSICATAS}

Alencar, M.E. 559 (10.2), 812 (5); Alves, L.J. 7 (10.1), 98 (7); Andrade-Lima, D. $62-4045$ (9), 1207 (7), 4988 (9); Araújo, A.P. 48, 49 , 408 (10.2); Araújo, B.R.N. 36 (10.2); Araújo, G.M. 382 (3); Arbo, M.M. 7482 (11); Barbeiro, S.M.C. 2709 (10.2). Bautista, H.P. 883 (7), 1448 (11), 3222 (10.2); Brito, H.S. 316 (4), 344 (10.1); Cardoso, D. 590 (10.2), 768 (3), 922 (7), 2965 (4); Carneiro-Torres, D.S. 633 (4); Carvalho, A.M.V. 1788 (10.1), 1822 (10.2), 2900 (11), 3708 (10.1), 4014 (4), 4044 (10.2), 4155 (10.2); Carvalho-Sobrinho, J.G. 697 (10.2), 1925 (5); Castro, J. 6 (10.2); Cavalcanti, T.B. 1111 (10.1); Conceição, A.A. 1502, 1550, 1560 (4), 2204 (10.2), 2336 (7), 2502 (10.2), 2729, 2794 (7), 2902 (11); Conceição, S.F. 648 (10.2); Correia, C. 351 (7); Costa, L.C.B. 74 (8); Dias, B.J. 21 (10.2); Eiten, G. 4183 (6); Faria, S.M. 427 (3), 431 (10.1), 436 (10.2), 1339 (7); Ferreira, F.M. 1410 (8); Ferreira, M.A. 504 (7); Ferreira, M.C. 504 (7), 1082 (10.2); Ferreira, P. 71 (9); Fiaschi, P. 1933 (8); Folli, D.A. 181 (1); Forzza, R.C. 1107, 1380 (10.1); Fotius, G. 3475 (11), 3737 (3); França, F. 1258 (10.2), 3293 (10.1), 3808 (10.2), 3954 (10.1). Freire-Fierro, A. 1808 (4), 1856 (7), 1966 (11); Giulietti, A.M. PCD 6074 (10.2); Gomes, F.S. 287, 323 (7); Gomes, T.B. 58 (7); Gouvêa, E. 16/88 (7); Gregório, B.S. 37 (7); Grillo, A.A. 164 (10.2); Groppo Jr., M. 733 (10.2); Guedes, M.L. 395 (4), 2678 (7), 2884 (7), 6754 (2), 6992, 7091, 7510, 7929 (7), 9449, 10313, 13391, 13521 (10.2), 13599 
(7), 13636 (10.2), 13914 (4), 13921, 13952, 13998, 14005, 14084 (7), 14100 (10.2), 14124, 14503, 14504, 14554, 15819, 16947 (7), PCD 2000 (10.1), PCD 2871 (3), PCD 5425 (10.1); Hage, J.L. 127 (2), 2335 (10.1); Harley, R.M. 10531 (10.1), 16752 (3), 16782 (4), 18644 (10.2), 19016 (4), 19808, 19831 (10.1), 19889 (7), 21115 (10.1), 21570(7), 53775, 54347 (11), 55805 (10.2), 55827 (7), PCD 3702 (3); Irwin, H.S. 31396 (10.1); Jardim, J.G. 3324 (10.2); Jordy Filho, S. 221 (10.2); Kirizawa, M. 326 (1); Lacerda, A.V. 258 , 536 (3); Leite, E.J. 47 (8); Leite, K.R.B. 108 (3), 384, 390 (11); Lewis, G.P. 1882 (7); Lima, H.C. 3934 (7), 3947 (4); Lopes, M.M.M. 1360 (7); Lordêlo, R.P. 57690 (7); Loureiro, D.M. 574 (4); Machado, M. 108 (6); Maciel, J.R. 1067 (10.2); Mariano, K.R.S. 4 (7); Martinelli, G. 16397 (10.1); Matos, E.N. 993 (8); Mattos Silva, L.A. 3207, 5053 (8); Meireles, J.E. 660 (7), 717 (10.1); Melo, E. 2701 (4), 3325 (10.2); Mendes, M.R.A. 222 (10.2); Mendonça, R.C. 1428, 2373 (10.2), 3250 (4), 4358 (10.1); Miranda, A.M. 173 (7), 3019, 6419 (4); Miranda, C.A 269 (4); Miranda, E.B. 218 (7); Monteiro, M.T. 22700 (9); Mori, S.A. 12992 (2); Nascimento Júnior, I.C. 361 (10.1); Nascimento, F.H.F. 178 (10.2); Neves, S.P.S. 212 (10.2); Nunes, M.S. 7, 8, 9 (3); Nunes, T.S. 509, 519, 714 (11), 922, 923 (7), 1111 (11), 1550 (10.2); Oliveira, A.A. 171 (7); Oliveira, F.C.A. 888 (4); Oliveira, R.P. 58 (10.2); Orlandi, R.P. 531 (11); Passos, L. PCD 4951 (10.1); PaulaSouza, J. 10029 (11); Pedralli, G. 3307 (10.1), 3315, 3354 (3); Pereira, B.A.S. 1643 (10.1). Pereira-Silva, G. 9168 (11); Pinheiro, R.S. 1932 (8); Pinto, G.C.P. (11). Queiroz, E.P. 2372, 3274 (7); Queiroz, L.P. 3373, 3447 (10.2), 3586 (7), 3614 (3), 3615,3640 , 3658 (7), 3663 (3), 3901 (4), 3937 (10.2), 3983 (11), 4171 (5), 4297, 4652 (10.2), 4804 (4), 4834 (7), 6092 (10.2), 6454, 7039, 7084(7), 7370 (4), 7404 (11), 7510, 7700 (10.2), 7711 (7), 7900, 7994, 8040, 8042, 9114, 9620 (11), 10296 (10.1), 10966 (4), 11005 (7), 12130, 13623 (10.2), 14730 (4), 15992 (10.2); Ramalho, F.B. 250 (7); Raw, A. 3287 (3); Ribeiro, T. 195 (10.1), 428 (10.2); Ribeiro-Filho, A.A. 239 (10.2); Rodarte, A.T.A. 127 (4), 136 (7); Rodrigues, M.T.U. s.n. SPF 81438 (4); Rylands, A. 72/1980 (2); Saar, E. 87 (7), PCD 5318 (4). Sambuichi, R.H.R. 1169A (1); Santana, D.L. 462 (10.2); Santana, F.A. 18 (10.2); Santos, A.A. 840 (2); Santos, F.S. 650 , 719 (2); Santos, R.M. 1359 (4); Santos, T.S. 1447 (8), 3089 (2), 3490 (7); Silva, F.B.L. 27 (7); Silva, F.H.M. 346 (7); Silva, G.P. 1132 (10.1), 3613 (10.2); Silva, N.C.B. 85 (10.1); Silva, S.B. 156 (4), 157 (3); Silva-Castro, M.M. 1428 (10.2); Siqueira-Filho, J.A. 1924 (11); Souza, E.R. 283 (7), 304 (3); Souza, I.M. 55 (7), 79 (10.2), 80, 81(3), 82, 83, 84, 85 (10.2), 89 (7), 90 (10.2), 91, 92, 93, 94 (3), 95, 98, 99,100 (10.2), 106 (3), 144 (10.2), 160 (8); Souza, V.C. 5378 (10.1); Stannard, B. 51706 (10.2); Thomas, M.B. MT553 (2); Tomasulo, P.L.B. 307 (1); Tourinho, R. 28 (3); Van den Berg, C. 1401 (10.2); Walter, B.M.T. 221, 1248, 4128 (10.1); Zehntner, L. 330 (5), 331 (7), 529 (4), 608 , s.n. RB 10902 (7). 